\title{
The Association of Intraoperative driving pressure with postoperative pulmonary complications in open versus closed abdominal surgery patients - a posthoc propensity score-weighted cohort analysis of the LAS VEGAS study
}

Guido Mazzinari ${ }^{1,2^{*}}$, Ary Serpa Neto ${ }^{3,4,5}$, Sabrine N. T. Hemmes ${ }^{5}$, Goran Hedenstierna ${ }^{6}$, Samir Jaber ${ }^{7}$, Michael Hiesmayr ${ }^{8}$, Markus W. Hollmann ${ }^{5}$, Gary H. Mills ${ }^{9}$, Marcos F. Vidal Melo ${ }^{10}$, Rupert M. Pearse ${ }^{11}$, Christian Putensen ${ }^{12}$, Werner Schmid ${ }^{8}$, Paolo Severgnini ${ }^{13}$, Hermann Wrigge ${ }^{14}$, Oscar Diaz Cambronero ${ }^{1,2}$, Lorenzo Ball ${ }^{15,16}$, Marcelo Gama de Abreu ${ }^{17}$, Paolo Pelosi ${ }^{15,16}$, Marcus J. Schultz ${ }^{5,18,19}$, for the LAS VEGAS studyinvestigators, the PROtective VEntilation NETwork and the Clinical Trial Network of the European Society of Anaesthesiology

\footnotetext{
Abstract

Background: It is uncertain whether the association of the intraoperative driving pressure $(\Delta P)$ with postoperative pulmonary complications (PPCs) depends on the surgical approach during abdominal surgery. Our primary objective was to determine and compare the association of time-weighted average $\Delta P\left(\Delta \mathrm{P}_{\mathrm{TW}}\right)$ with PPCs. We also tested the association of $\Delta \mathrm{P}_{\mathrm{TW}}$ with intraoperative adverse events.

Methods: Posthoc retrospective propensity score-weighted cohort analysis of patients undergoing open or closed abdominal surgery in the 'Local ASsessment of Ventilatory management during General Anaesthesia for Surgery' (LAS VEGAS) study, that included patients in 146 hospitals across 29 countries. The primary endpoint was a composite of PPCs. The secondary endpoint was a composite of intraoperative adverse events.

(Continued on next page)
}

\footnotetext{
*Correspondence: gmazzinari@gmail.com

${ }^{1}$ Research Group in Perioperative Medicine, Hospital Universitario y

Politécnico la Fe, Avinguda de Fernando Abril Martorell 106, 46026 Valencia,

Spain

${ }^{2}$ Department of Anesthesiology, Hospital Universitario y Politécnico la Fe,

Valencia, Spain

Full list of author information is available at the end of the article
}

(c) The Author(s). 2021 Open Access This article is licensed under a Creative Commons Attribution 4.0 International License, which permits use, sharing, adaptation, distribution and reproduction in any medium or format, as long as you give appropriate credit to the original author(s) and the source, provide a link to the Creative Commons licence, and indicate if changes were made. The images or other third party material in this article are included in the article's Creative Commons licence, unless indicated otherwise in a credit line to the material. If material is not included in the article's Creative Commons licence and your intended use is not permitted by statutory regulation or exceeds the permitted use, you will need to obtain permission directly from the copyright holder. To view a copy of this licence, visit http://creativecommons.org/licenses/by/4.0/ The Creative Commons Public Domain Dedication waiver (http://creativecommons.org/publicdomain/zero/1.0/) applies to the data made available in this article, unless otherwise stated in a credit line to the data. 
(Continued from previous page)

Results: The analysis included 1128 and 906 patients undergoing open or closed abdominal surgery, respectively. The PPC rate was $5 \%$. $\Delta \mathrm{P}$ was lower in open abdominal surgery patients, but $\Delta \mathrm{P}_{\text {Tw }}$ was not different between groups. The association of $\Delta P_{T W}$ with PPCs was significant in both groups and had a higher risk ratio in closed compared to open abdominal surgery patients $(1.11$ [95\%Cl 1.10 to 1.20$], P<0.001$ versus 1.05 [95\%Cl 1.05 to 1.05$], P<0.001$; risk difference 0.05 [95\% Cl 0.04 to 0.06], $P<0.001$ ). The association of $\Delta P_{\text {TW }}$ with intraoperative adverse events was also significant in both groups but had higher odds ratio in closed compared to open abdominal surgery patients (1.13 [95\%Cl 1.12- to 1.14], $P<0.001$ versus 1.07 [95\% Cl 1.05 to 1.10$], P<0.001$; risk difference 0.05 [95\% Cl 0.030.07], $P<0.001)$.

Conclusions: $\triangle P$ is associated with PPC and intraoperative adverse events in abdominal surgery, both in open and closed abdominal surgery.

Trial registration: LAS VEGAS was registered at clinicaltrials.gov (trial identifier NCT01601223).

Keywords: Pneumoperitoneum, Laparoscopy, Laparoscopic surgery, Perioperative ventilation, Protective ventilation, PEEP, Respiratory mechanics, Driving pressure

\section{Introduction}

The incidence of postoperative pulmonary complications (PPCs) is high and depends on the used definitions and the studied population [1]. Their occurrence is associated with increased morbidity and mortality $[2,3]$. PPCs can be prevented by reducing lung strain by using a low tidal volume $\left(\mathrm{V}_{\mathrm{T}}\right)[4]$, , and by using sufficient positive end-expiratory pressure (PEEP) [5]. Since the driving pressure $(\Delta \mathrm{P})$, defined as the difference between plateau pressure and PEEP, is associated with the development of PPCs $[5,6]$, titrating $\mathrm{V}_{\mathrm{T}}$ and PEEP to obtain the lowest $\triangle \mathrm{P}$ could be an effective preventive strategy against PPCs.

The overall behaviour of the respiratory system depends on the properties of its components, i.e., the artificial and native airways, and the lung tissue, but also the chest wall consisting of the rib cage and diaphragm. Most of the force applied during invasive ventilation is needed to expand the chest wall, and only a lesser amount to inflate lung tissue [7]. When the chest wall elastance increases, e.g., during pneumoperitoneum, the $\Delta \mathrm{P}$ increases, even when $\mathrm{V}_{\mathrm{T}}$ is left unchanged [8]. This rise in $\Delta \mathrm{P}$ is often interpreted as 'innocent', and therefore accepted during intraoperative pneumoperitoneum. However, the cephalad shift of the diaphragm could induce, or worsen atelectases during intraoperative ventilation, and the resulting increase in $\Delta \mathrm{P}$ is related with a rise in lung applied force [9]. In other words, it should be questioned if a rise in $\Delta \mathrm{P}$ during pneumoperitoneum with closed abdominal surgery can be accepted.

To determine and compare the independent associations of $\triangle \mathrm{P}$ with PPCs in patients undergoing open abdominal surgery versus patients undergoing closed abdominal surgery, we reassessed the database of the 'Local ASsessment of Ventilatory management during General Anaesthesia for Surgery' (LAS VEGAS) study [10]. The LAS VEGAS study was a large observational study that included a large proportion of patients at an increased risk for PPCs. The primary hypothesis tested here was that the association of $\triangle \mathrm{P}$ with PPCs is weaker in closed versus open abdominal surgery patients. The primary objective was to test the association of a timeweighted average driving pressure $\left(\Delta \mathrm{P}_{\mathrm{TW}}\right)$ with PPCs. The secondary objective was to test the association of $\Delta \mathrm{P}_{\mathrm{TW}}$ with intraoperative adverse events.

\section{Methods}

\section{Study design and setting}

This is a posthoc analysis of the LAS VEGAS study [10], carried out following current guidelines and the recommendations of the statement for strengthening the reporting of observational studies in epidemiology (STROBE) (www.strobe-statemenent.org). The statistical analysis plan was predefined, updated, and finalised before data extraction, and is presented as Additional file 1. The LAS VEGAS study is a worldwide international multicentre prospective seven-day observational study describing intraoperative ventilation practice, complications during anaesthesia, PPCs in the first five postoperative days, hospital length of stay, and hospital mortality.

The ethical committee of the Academic Medical Center, Amsterdam, the Netherlands, approved the LAS VEGAS study protocol (W12_190\#12.17.0227). Each participating centre obtained approval from their institutional review board if needed, and patients were included after obtaining written informed consent when dictated by national or regional legislation. The LAS VEGAS study was partially funded and endorsed by the European Society of Anaesthesiology and registered at clinicaltrials.gov (study identifier NCT01601223, first posted date: 17/05/2012).

\section{Inclusion and exclusion criteria}

The LAS VEGAS study recruited consecutive patients undergoing general anaesthesia with mechanical 
ventilation during anaesthesia for surgery during a seven-days timeframe between 14 January and 4 March 2013. Exclusion criteria of the LAS VEGAS study were: (1) age $<18$ years, (2) having received mechanical ventilation in the preceding month, (3) obstetric or ambulatory surgical interventions, and (4) cardiothoracic surgery cardiopulmonary bypass.

For the current analysis, inclusion was restricted to patients undergoing abdominal surgery. The following additional exclusion criteria were used: (1) insufficient data to calculate $\Delta \mathrm{P}$, i.e., on at least two timepoints sufficient data had to be available to calculate the driving pressure for a patient to be included; (2) to increase the homogeneity of the compared patient cohorts and avoid using erroneous data, patients who received intraoperative ventilation through an airway device other than an endotracheal tube as well as patients under an assisted or spontaneous ventilation mode were excluded; (3) patients in whom laparoscopy only assisted the surgery, i.e., surgeries that could not be classified as mere open or mere closed abdominal surgery, were also excluded from the current analysis.

\section{Data recording and calculations}

Full details on data collection can be found in the original publication of the LAS VEAGS study [10], and in Additional file 2. In the LAS VEGAS study database, ventilatory parameters at every hour of surgery, from induction up to the last hour of surgery, were recorded. Data in the LAS VEGAS database was validated through two rounds of extensive data cleaning to check for invalid or incomplete data. Local investigators were queried on incorrect or missing data and had to correct those in the cleaning rounds.

The following calculations were performed. $\Delta \mathrm{P}$ was calculated by subtracting PEEP from plateau pressure or inspiratory pressure at every hour in volume-controlled and pressure-controlled ventilated patients, respectively. $\Delta \mathrm{P}_{\mathrm{TW}}$, i.e., the pressure that is proportional to the amount of time spent at each driving pressure in relation to the total time, was calculated by summing the mean values between consecutive time points multiplied by the time between those points and then dividing by the entire time [11]. Similarly, time-weighted average peak pressure and PEEP were determined. Details on calculations are provided in the Additional file 2 Figure S1.

\section{Definitions}

PPCs were defined as a collapsed composite of the following events: unexpected postoperative invasive or non-invasive ventilation, acute respiratory failure, acute respiratory distress syndrome, pneumonia, and pneumothorax. The occurrence of each type of complication was monitored until hospital discharge but restricted to the first five postoperative days.

Intraoperative adverse events were defined as an ordinal composite of the following events: any oxygen desaturation or lung recruitment manoeuvres performed to rescue from hypoxemia, any need for adjusting ventilator settings for reducing airway pressures or correction of expiratory flow limitation, any hypotension or need for vasoactive drugs, and any new cardiac arrhythmia.

A detailed list of definitions of the composites of PPCs and intraoperative adverse events is provided in Additional file 2 Table S1 and Table S2.

\section{Endpoints}

The primary endpoint was the composite of PPCs. The secondary endpoint was the composite of intraoperative adverse events.

\section{Analysis plan}

The analysis plan was prespecified before data access, and we used data of all available patients in the LAS VEGAS database without formal sample size calculation. Also, as the purpose of the analysis was exploring a physiological hypothesis, we did not specify any a priori effect size.

Continuous variables were reported as median and interquartile ranges; categorical variables expressed as $n$ (\%). Normality of distributions was assessed by inspecting quantile-quantile plots. If variables were normally distributed, the two-sample t-test was used; if not, the Wilcoxon rank sum test was used. We used the Chisquare test or Fisher's exact test for categorical variables, or when appropriate, as relative risks. Statistical uncertainty was expressed by showing the $95 \%$-confidence intervals (CI). Since the simultaneous occurrence of various intraoperative adverse events is frequent, we analysed them as an ordinal variable with a range spanning from zero to seven adverse events.

To control for confounding effects, we estimated the association of $\Delta \mathrm{P}_{\mathrm{TW}}$ with $\mathrm{PPC}$ with a weighted mixedeffect logistic regression, and the association of $\Delta \mathrm{P}_{\mathrm{TW}}$ with intraoperative adverse events with a weighted mixed ordinal regression. To fit the models, we introduced centres as a random intercept, and an inverse probability weighting factor computed from the covariate-balancing propensity score (CBPS) method to simultaneously optimise treatment assignment prediction, i.e., $\Delta \mathrm{P}_{\mathrm{TW}}$ as a continuous variable, and confounders influence [12]. The CBPS procedure sets mean independence between treatment, i.e., $\Delta \mathrm{P}_{\mathrm{TW}}$, and covariates to ensure covariate balancing and estimates the propensity score with the generalised method of moments method. For both outcomes, we fitted the model for each of the compared patient cohorts respectively, i.e., patients who 
underwent open surgery intervention and those who underwent closed surgical intervention. We used a Wald z-test to test the difference between odds ratios from models fitted on closed and open surgery cohort. Models' goodness of fit was assessed by residual diagnosis based on scaled quantile residuals ( $\mathrm{R} D H A R M a$ package v. 0.2.4) and simulated residuals ( $\mathrm{R}$ sure package $\mathrm{v}$ 0.2.0) for logistic and ordinal models, respectively.

To build the CBPS to relate exposure variable, i.e., $\Delta \mathrm{P}_{\mathrm{TW}}$, with potential confounders, we included by clinical judgment the Assess Respiratory Risk in Surgical Patients in Catalonia (ARISCAT) risk class [13, 14], and the average intraoperative $V_{T}$. Then we performed feature selection with an augmented backward elimination selection method introducing 37 preoperative and intraoperative variables (Additional file 2:Statistics for a detailed list). The selection was based on a sequential process where initially all variables entered the model and finally those preoperative and intraoperative factors that yielded a change in the effect estimate $>0.1$ and a significance criterion (alpha) $<0.1$ were included. The algorithm stopped when all variables left in the model complied with both criteria [15]. We carried out a selection process of potential variables to avoid bias in the effect estimates using a comprehensive strategy to prevent the drawbacks of simple stepwise methods [16]. The model's internal validation was assessed by bootstrap using 5 hundred generated samples and estimating the Area Under Curve (AUC) of the full and stepwise-selected variables models.

To further unravel the effect of the surgical approach on PPCs, we performed a sensitivity analysis fitting a mixed logistic regression with a random intercept for centre on a propensity score matched cohort. The propensity score was used to match patients with a similar covariable structure using the $\mathrm{R}$ matchit package carrying out the matching with the nearest neighbour method with a caliper of 0.1 with a ratio of patients in the open surgery arm of 2 to 1. Full details on the covariables introduced in the propensity score matching procedure can be found in the Additional file 2: Statistics. To assess the type of surgery as an effect modifier, we carried out another sensibility analysis fitting a weighted mixed logistic regression model on all data, i.e., both surgery cohorts, introducing the type of surgery as an independent variable and an interaction term between $\Delta \mathrm{P}_{\mathrm{TW}}$ and type of surgery.

Statistical significance was considered for two-tailed $P<0.05$. No imputation routine of missing values and no correction for multiple comparisons was prespecified; thus, all the findings should be viewed as exploratory. All analyses were performed with R 3.5.2 (The R Foundation for Statistical Computing, www.r-project.org). Additional explanation on the used methods can be found in the Additional file 2: Statistics.

\section{Results}

Patients

Of a total of 3265 patients undergoing abdominal surgery in the LAS VEGAS study, 1231 had insufficient data for calculating the $\triangle \mathrm{P}(37.7 \%)$.

Out of the remaining 2034 patients, 1218 (60\%) patients underwent an open abdominal intervention, and 906 (40\%) patients, a closed abdominal surgical procedure (Fig. 1). $\Delta \mathrm{P}$ could be calculated on two different timepoints in 34.4 and $53.7 \%$ of patients in the open and closed surgery group, respectively (Fig. 2 and Table S3). In $87 \%$ of patients, $\Delta \mathrm{P}$ could be calculated on up to four timepoints.

Baseline demographic data, surgery-related and intraoperative ventilation characteristics are presented in Tables 1 and 2, and Fig. 2. Open abdominal surgery patients had higher ASA class and ARISCAT risk score, lower functional status, and fewer elective procedures, longer surgery times, less neuromuscular reversals, and received more intraoperative transfusions and fluids. Lower abdomen surgeries were the most frequently performed in the open abdominal surgery patients, while upper abdomen interventions were performed more often in closed abdominal surgery patients. $\Delta \mathrm{P}_{\mathrm{TW}}$ was not different between the open and closed surgery groups (Table 2).

\section{Primary and secondary outcome rates}

In 102 (5\%) patients, one or more PPC occurred, with a higher prevalence in open surgery patients than in patients who underwent a closed surgical procedure (7 versus 3\%; $P<0.001)$. Hypotension, or need for vasopressors was more frequently observed during open surgery, while the need for airway pressure reduction was more often needed during closed surgery (Table 3).

\section{Propensity score estimation variables}

The variables that finally entered the propensity score and covariate balance assessment are detailed in the Additional file 2: Statistics and Fig. S2 and S3.

\section{Association of $\Delta \mathrm{P}_{\mathrm{TW}}$ with PPCs}

$\Delta \mathrm{P}_{\mathrm{TW}}$ was significantly associated with PPCs in both surgical groups. The association was stronger in closed abdominal surgery patients (odds ratio (OR), 1.17 [95\%CI 1.16 to 1.19 ]; $P<0.001$; risk ratio (RR), 1.11 [95\%CI 1.10 to 1.20 ], $P<0.001)$ than in patients who underwent an open abdominal surgical intervention (OR, 1.07 [95\%CI 1.06 to 1.08 ]; $P<0.001$; RR 1.05 [95\% CI 1.05 to 1.05 ]), with a significant difference (difference between ORs: 0.09 [95\%CI 0.07 to 0.10]; $P<0.001$; risk difference 0.05 : [95\%CI 0.04 to 0,06$]), P<0.001$. Residuals plots are reported in Additional file 2: Figure S4. 


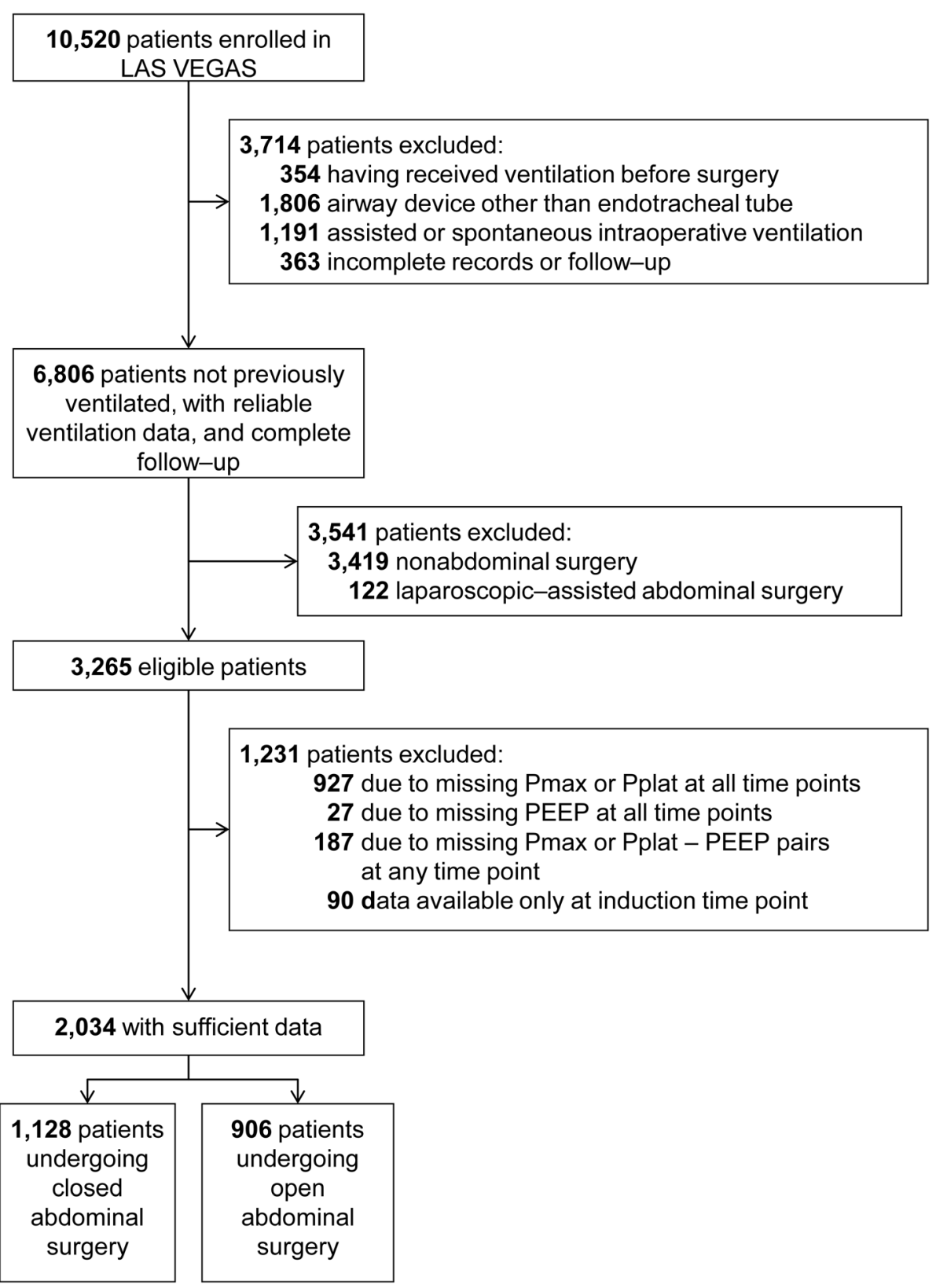

Fig. 1 Patients' inclusion flowchart

\section{Association of $\Delta \mathrm{P}_{\mathrm{TW}}$ with the occurrence of adverse events}

$\Delta \mathrm{P}_{\mathrm{TW}}$ was significantly associated with intraoperative adverse events in both open and closed surgery patients. Also, here the association was stronger in closed surgery patients (1.13 [95\%CI 1.12 to 1.14]) than in patients who underwent an open abdominal intervention (1.07 [95\%CI 1.05 to 1.10]), difference between ORs 0.05 [95\%CI 0.03 to 0.07 ]; $P<0.001$.

\section{Sensitivity analyses}

$\Delta \mathrm{P}_{\mathrm{TW}}$ was significantly associated with PPCs (OR, 1.08 [95\%CI 1.06 to 1.09 ], $P<0.001)$ with closed surgery patients having a lower probability of occurrence (OR, 0.14 [ $95 \%$ CI 0.12 to $0.16, P<0.001$ ) with a significant interaction between $\Delta \mathrm{P}_{\mathrm{TW}}$ and closed surgery (OR, 1.09 [95\%CI 1.08 to 1.11 ],$P<0.001$ ). The marginal effect of $\Delta \mathrm{P}_{\mathrm{TW}}$ by type of surgery on PPCs probability is showed in Fig. 3. A rise in $\Delta \mathrm{P}_{\mathrm{TW}}$ was associated with an increased probability of PPCs in both surgery types, with a steeper increase in closed surgery patients for $\Delta \mathrm{P}_{\mathrm{TW}}$ above $20 \mathrm{cmH}_{2} \mathrm{O} \cdot$ hour $^{-1}$.

After matching, the resulting cohort consisted of 344 open surgery patients and 254 closed surgery patients. Baseline characteristics between groups were well 

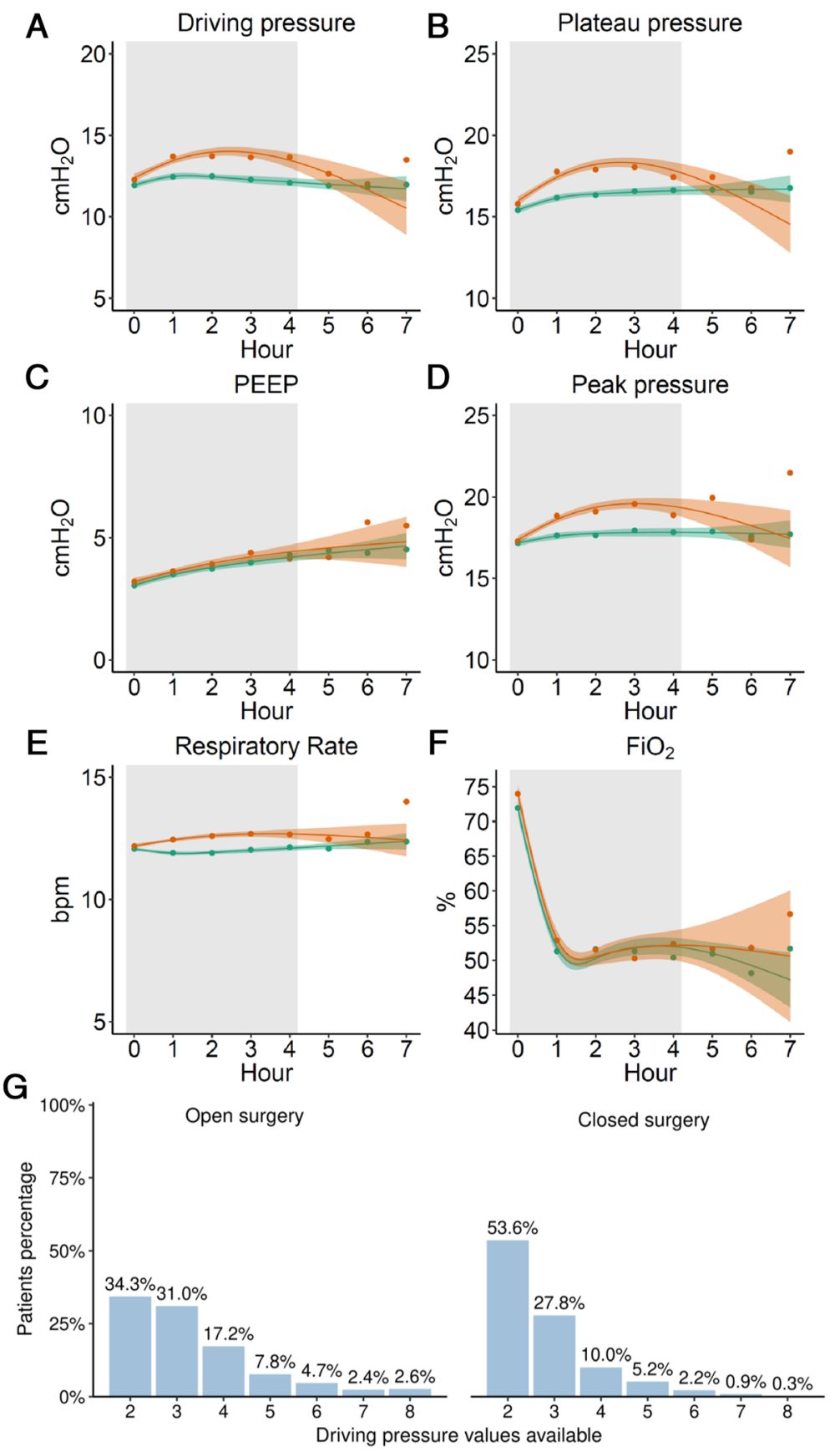

Fig. 2 Mechanical ventilation settings over time. Green: open surgery, Orange: closed surgery. Hour $0 \mathrm{~h}$ represents the induction of general anaesthesia. Solid lines are means, and bandwidths is 95\% bootstrapped confidence intervals. Gray boxes: More than 95\% of data points represented

balanced (Additional file 2: Table S4 and S5). Type of surgery at matched levels of driving pressure was not associated with either outcome. (Additional file 2: Table S5 and S6).

\section{Discussion}

The main findings of this posthoc analysis of the LAS VEGAS study can be summarised as follows: (i.) the intraoperative $\Delta \mathrm{P}_{\mathrm{TW}}$ was not different between open and closed surgery groups; (ii.) $\Delta \mathrm{P}_{\mathrm{TW}}$ was associated with PPCs in both closed and open surgery patients; (iii.) $\Delta \mathrm{P}_{\mathrm{TW}}$ was associated with intraoperative adverse events in both closed and open surgery patients; and (iv.) the type of surgery had a modifying effect on the association between $\Delta \mathbf{P}_{\mathbf{T W}}$ and PPCs, with an increasing probability of PPCs at high $\Delta \mathrm{P}_{\mathrm{TW}}$ in closed surgery. The last 
Table 1 Patients demographics and surgery-related characteristics

\begin{tabular}{|c|c|c|c|c|c|}
\hline & $\begin{array}{l}\text { All patients } \\
(N=2.034)\end{array}$ & $\begin{array}{l}\text { Closed } \\
\text { abdominal surgery } \\
(N=906)\end{array}$ & $\begin{array}{l}\text { Open } \\
\text { abdominal surgery } \\
(N=1.128)\end{array}$ & $P$-value & Absolute Difference \\
\hline Age, years & 54 [40 to 67] & $49[36$ to 64$]$ & 58 [45 to 69] & $<0.001$ & $9[6$ to 21$]$ \\
\hline Gender, male (\%) & $42 \%(846 / 2034)$ & $34 \%(306 / 906)$ & $48 \%(540 / 1128)$ & $<0.001$ & $14 \%$ [9 to $18 \%$ ] \\
\hline Ethnicity, \% (n/N) & & & & 0.194 & \\
\hline Caucasian & $88 \%(1787 / 2.030)$ & $87 \%(786 / 902)$ & $89 \%(1001 / 1.128)$ & & \\
\hline Black & $1 \%(20 / 2.030)$ & $1 \%(6 / 902)$ & $1 \%(14 / 1.128)$ & & \\
\hline Asian & $3 \%(58 / 2.030)$ & $4 \%(33 / 902)$ & $2 \%(25 / 1.128)$ & & \\
\hline Other & $8 \%(165 / 2.030)$ & $8 \%(77 / 902)$ & $8 \%(88 / 1.128)$ & & \\
\hline BMI $\left(\mathrm{Kg} \cdot \mathrm{m}^{-2}\right)$ & $26.2[23.3$ to 30.0$]$ & 26.7 [23.6 to 31.3$]$ & 25.8 [22.9 to 29.3] & $<0.001$ & 0.8 [0.04 to 1.6$]$ \\
\hline Weight (kg) & $75.0[65.0$ to 87.0$]$ & $77.0[68.0$ to 93.0$]$ & $74.0[64.0$ to 85.0$]$ & 0.001 & 3 [8 to 13$]$ \\
\hline PBW (kg) & $60.6[55.1$ to 69.0$]$ & $59.7[54.2$ to 67.8$]$ & $61.5[56.0$ to 69.7$]$ & $<0.001$ & $1.82[1.8$ to 2$]$ \\
\hline ASA class, $\%(n / N)$ & & & & $<0.001$ & \\
\hline 1 & $24 \%(495 / 2.028)$ & $31 \%(276 / 904)$ & $20 \%(219 / 1.124)$ & & \\
\hline 2 & 49\% (989/2.028) & $53 \%(477 / 904)$ & $46 \%(512 / 1.124)$ & & \\
\hline 3 & $24 \%(488 / 2.028)$ & $16 \%(146 / 904)$ & $30 \%(342 / 1.124)$ & & \\
\hline 4 & $3 \%(53 / 2.028)$ & $1 \%(5 / 904)$ & $4 \%(48 / 1.124)$ & & \\
\hline 5 & $0 \%(3 / 2.028)$ & $0 \%(0 / 904)$ & $0 \%(3 / 1.124)$ & & \\
\hline ARISCAT score & 26 [18 to 38$]$ & 18 [15 to 31$]$ & 34 [18 to 41] & $<0.001$ & 16 [16 to 16$]$ \\
\hline ARISCAT class, $\%(n / N)$ & & & & $<0.001$ & \\
\hline$<26$ & $51 \%(985 / 1.945)$ & $68 \%(607 / 888)$ & $36 \%(378 / 1.057)$ & & \\
\hline $26-44$ & $38 \%(741 / 1.945)$ & $26 \%(231 / 888)$ & $48 \%(510 / 1.057)$ & & \\
\hline$>44$ & $11 \%(219 / 1.945)$ & $6 \%(50 / 888)$ & $16 \%(169 / 1.057)$ & & \\
\hline Preop. $\mathrm{SpO}_{2}, \%$ & 98 [96 to 99] & 98 [96 to 99] & 97 [96 to 99] & 0.004 & $0[0$ to 3$]$ \\
\hline Current smoker, \% & $20 \%(413 / 2.034)$ & $21 \%(79 / 906)$ & $20 \%(222 / 1.128)$ & 0.468 & $2 \%$ [3 to $7 \%]$ \\
\hline \multicolumn{6}{|l|}{ Chronic comorbidity, \% (n/N) } \\
\hline Metastatic cancer & $7 \%(138 / 2.034)$ & $2 \%(22 / 906)$ & $10 \%(116 / 1.128)$ & $<0.001$ & $8 \%$ [5 to $9 \%]$ \\
\hline Chronic kidney failure & $4 \%(81 / 2.034)$ & $1 \%(13 / 906)$ & $6 \%(68 / 1.128)$ & $<0.001$ & $5 \%$ [2 to $6 \%]$ \\
\hline COPD & $7 \%(138 / 2.034)$ & $7 . \%(83 / 906)$ & $6 \%(55 / 1.128)$ & 0.290 & $1 \%[1$ to $3 \%]$ \\
\hline Heart failure & $7 \%(143 / 2.034)$ & $6 \%(53 / 906)$ & $8 \%(90 / 1.128)$ & 0.075 & $2 \%$ [1 to $4 \%]$ \\
\hline OSAS & $2 \%(42 / 2.034)$ & $3 \%(27 / 906)$ & $1 \%(15 / 1.128)$ & 0.015 & $2 \%[1$ to $3 \%]$ \\
\hline Neuromuscular disease ${ }^{a}$ & $1 \%(17 / 2.034)$ & $1 \%(6 / 906)$ & $1 \%(11 / 1.128)$ & 0.599 & $0.3 \%$ [0.3 to $1 \%]$ \\
\hline Liver dysfunction & $1 \%(29 / 2.034)$ & $1 \%(5 / 906)$ & $2 \%(24 / 1.128)$ & 0.210 & $1 \%[1$ to $2 \%]$ \\
\hline Functional Status, \% (n/N) & & & & $<0.001$ & \\
\hline Independent & $92 \%(1872 / 2.034)$ & $96 \%(867 / 906)$ & $89 \%(1005 / 1.128)$ & & \\
\hline Partially dependent & $7 \%(135 / 2.034)$ & $4 \%(32 / 906)$ & $9 \%(103 / 1.128)$ & & \\
\hline Totally dependent & $1 \%(27 / 2.034)$ & $1 \%(7 / 906)$ & $2 \%(20 / 1.128)$ & & \\
\hline Preop. resp. infection, $\%(n / N)$ & $5 \%(95 / 2.034)$ & $4 \%(35 / 906)$ & $5 \%(60 / 1.128)$ & 0.150 & $2 \%[0.5$ to $3 \%]$ \\
\hline Preop. $\mathrm{Hb}\left(\mathrm{g} \cdot \mathrm{dl}^{-1}\right), \%(\mathrm{n} / \mathrm{N})$ & $13.4[12.2$ to 14.0$]$ & 13.512 .6 to 14.5$]$ & $13.3[11.9$ to 14.5$]$ & $<0.001$ & $0.2[0.3$ to 1$]$ \\
\hline Preop. anemia $\left(\mathrm{Hb} \leq 10 \mathrm{~g} \mathrm{dl}^{-1}\right)$ & $9 \%(1738 / 1.846)$ & $3 \%(21 / 798)$ & $8 \%(87 / 1.048)$ & $<0.001$ & $5 \%$ [3 to $7 \%]$ \\
\hline Preop. creatinine $\left(\mathbf{g} \cdot \mathrm{dl}^{-1}\right)$ & $0.8[0.7$ to 1.0$]$ & $0.8[0.7$ to 1.0$]$ & $0.9[0.7$ to 1.1$]$ & $<0.001$ & $0.04[0.01$ to 0.1$]$ \\
\hline Preop transfusion, $\%(\mathrm{n} / \mathrm{N})$ & $1 \%(23 / 2.034)$ & $0 \%(3 / 906)$ & $2 \%(20 / 1.128)$ & 0.004 & $1 \%[0.5$ to $1 \%]$ \\
\hline \multicolumn{6}{|l|}{ Surgical procedure ${ }^{b}, \%(n / N)$} \\
\hline Lower Gl & $26 \%(286 / 1.098)$ & $14 \%(124 / 906)$ & $31 \%(346 / 1.128)$ & $<0.001$ & $17 \%$ [13 to $20 \%]$ \\
\hline Upper GI, HBP & $28 \%(303 / 1.098)$ & $47 \%(429 / 906)$ & $20 \%(222 / 1.128)$ & $<0.001$ & $27 \%$ [23 to $31 \%]$ \\
\hline
\end{tabular}


Table 1 Patients demographics and surgery-related characteristics (Continued)

\begin{tabular}{|c|c|c|c|c|c|}
\hline & $\begin{array}{l}\text { All patients } \\
(N=2.034)\end{array}$ & $\begin{array}{l}\text { Closed } \\
\text { abdominal surgery } \\
(N=906)\end{array}$ & $\begin{array}{l}\text { Open } \\
\text { abdominal surgery } \\
(N=1.128)\end{array}$ & $P$-value & Absolute Difference \\
\hline Vascular surgery & $2 \%(25 / 1.098)$ & $0 \%(0 / 906)$ & $3 \%(30 / 1.128)$ & $<0.001$ & $2 \%$ [1 to $3 \%]$ \\
\hline Aortic surgery & $2 \%(19 / 1.098)$ & $0 \%(0 / 906)$ & $2 \%(20 / 1.128)$ & $<0.001$ & $1 \%[1$ to $2 \%]$ \\
\hline Urological & $19 \%(204 / 1.098)$ & $9 \%(81 / 906)$ & $14 \%(162 / 1.128)$ & $<0.001$ & $5 \%$ [2 to $8 \%]$ \\
\hline Gynaecological & $18 \%(195 / 1.098)$ & $26 \%(233 / 906)$ & $17 \%(188 / 1.128)$ & $<0.001$ & $9 \%$ [6 to $12 \%]$ \\
\hline Endocrine surgery & $1 \%(9 / 1.098)$ & $1 \%(5 / 906)$ & $1 \%(10 / 1.128)$ & 0.443 & $0.3 \%[0.5$ to $1 \%]$ \\
\hline Transplant & $2 \%(18 / 1.098)$ & $0 \%(0 / 906)$ & $2 \%(20 / 1.128)$ & $<0.001$ & $2 \%[1$ to $3 \%]$ \\
\hline Neurosurgery & $5 \%(52 / 1.098)$ & $0 \%(1 / 906)$ & $10 \%(109 / 1.128)$ & $<0.001$ & $9 \%$ [8 to $11 \%]$ \\
\hline Other procedure & $3 \%(30 / 1.098)$ & $5 \%(43 / 906)$ & $19 \%(214 / 1.128)$ & $<0.001$ & $14 \%$ [11 to $17 \%]$ \\
\hline Urgency of Surgery $\%(n / N)$ & & & & $<0.001$ & \\
\hline Elective & $84 \%(1705 / 2.034)$ & $87 \%(792 / 906)$ & $81 \%(913 / 1.128)$ & & \\
\hline Urgent & $12 \%(235 / 2.034)$ & $9 \%(85 / 906)$ & $13 \%(150 / 1.128)$ & & \\
\hline Emergency & $4 \%(94 / 2.034)$ & $4 \%(29 / 906)$ & $6 \%(65 / 1.128)$ & & \\
\hline Duration of surgery ${ }^{d}, \min$ & 86 [55 to 149$]$ & $70[50$ to 110$]$ & $105[65$ to 172$]$ & $<0.001$ & 35 [21 to 43$]$ \\
\hline Duration of anaesthesia ${ }^{\mathrm{e}}, \mathrm{min}$ & 115 [80 to 190] & $100[71$ to 147$]$ & 140 [91 to 205] & $<0.001$ & 40 [20 to 60$]$ \\
\hline Time of surgery, \% (n/N) & & & & $<0.843$ & $0.2[0.2$ to 1$]$ \\
\hline Daytime $^{f}$ & $95 \%(1925 / 2034)$ & $95 \%(859 / 906)$ & $95 \%(1066 / 1128)$ & & \\
\hline Night-time & $5 \%(109 / 2034)$ & $5 \%(47 / 906)$ & $5 \%(962 / 1128)$ & & \\
\hline Antibiotic prophylaxis, \% (n/N) & $80 \%(1.628 / 2.034)$ & $73 \%(662 / 906)$ & $84 \%(956 / 1.127)$ & 0.005 & $11 \%$ [8 to $15 \%]$ \\
\hline Mean arterial pressure, $\mathrm{mmHg}$ & 82 [74 to 92$]$ & 84 [76 to 94$]$ & 80 [72 to 90$]$ & $<0.001$ & $4[4$ to 7$]$ \\
\hline Heart rate, beats $\cdot \min$ & 72 [63 to 82$]$ & 73 [64 to 82$]$ & 72 [62 to 83] & 0.276 & $1[3$ to 11$]$ \\
\hline \multicolumn{6}{|l|}{ Intraop. procedures, \% (n/N) } \\
\hline Epidural anesthesia & $12 \%(237 / 2.034)$ & $3 \%(25 / 906)$ & $19 \%(212 / 1128)$ & $<0.001$ & $16 \%$ [13 to $18 \%]$ \\
\hline Opioid & & & & $<0.001$ & \\
\hline Short-acting & $18 \%(367 / 2.015)$ & $22 \%(193 / 900)$ & $16 \%(174 / 1.115)$ & & \\
\hline Long-acting & $70 \%(1410 / 2.015)$ & $62 \%(561 / 900)$ & $76 \%(849 / 1.115)$ & & \\
\hline Both & $12 \%(238 / 2.015)$ & $16 \%(146 / 900)$ & $8 \%(92 / 1.115)$ & & \\
\hline Neuromuscular Blockade & $97 \%(1965 / 2.028)$ & $97 \%(876 / 903)$ & $97 \%(1089 / 1.125)$ & 0.887 & $0.2 \%[0.1$ to $1 \%]$ \\
\hline Neuromuscular Monitoring & $23 \%(474 / 2.032)$ & $25 \%(230 / 906)$ & $22 \%(244 / 1.126)$ & 0.055 & $3 \%[0$ to $7 \%]$ \\
\hline Neuromuscular Reversal & $41 \%(827 / 2.024)$ & $49 \%(437 / 901)$ & $35 \%(390 / 1.123)$ & $<0.001$ & $14 \%$ [9 to $18 \%]$ \\
\hline TIVA & $10 \%(211 / 2.027)$ & $11 \%(102 / 902)$ & $10 \%(109 / 1.125)$ & 0.266 & $1 \%$ [1 to $4 \%]$ \\
\hline Transfusion & $6 \%(113 / 2.034)$ & $1 \%(13 / 906)$ & $9 \%(100 / 1.128)$ & $<0.001$ & $7 \%$ [6 to 9\%] \\
\hline Total Fluids $\left(\mathrm{mL} \cdot \mathrm{kg}^{-1}\right)$ & 18 [12 to 30$]$ & 15 [13 to 30$]$ & 23 [14 to 26$]$ & $<0.001$ & $8[6$ to 10$]$ \\
\hline Crystalloids $\left(\mathrm{mL} \cdot \mathrm{kg}^{-1}\right)$ & 17 [12 to 26$]$ & 14 [11 to 21$]$ & 20 [13 to 31] & $<0.001$ & $5[4$ to 7$]$ \\
\hline Colloids $\left(\mathrm{mL} \cdot \mathrm{kg}^{-1}\right)$ & 7 [3 to 9] & 4 [0 to 7$]$ & 7 [6 to 12$]$ & $<0.001$ & 3 [2 to 6$]$ \\
\hline
\end{tabular}

Data are presented as median [25th-75th percentile] or \% $(\mathrm{n} / \mathrm{N})$. For binary and continuous variables risk difference and median difference with $95 \%$ confidence intervals in square brackets are reported respectively

Abbreviations: BMI Body mass index, ASA American Society of Anaesthesiologists, ARISCAT Assess Respiratory Risk in Surgical Patients in Catalonia risk index, ${ }^{14,15}$ $\mathrm{Hb}$ Haemoglobin, Gl Gastrointestinal, $\mathrm{HBP}$ Hepatobiliopancreatic, $\mathrm{SpO}_{2}$ Peripheral oxygen saturation, $\mathrm{Cl}$ Confidence interval, COPD Chronic Obstructive Pulmonary Disease, OSAS Obstructive sleep apnea sydnrome, TIVA Total Intravenous Anaesthesia

${ }^{\text {a }}$ Neuromuscular disease affecting the respiratory system

${ }^{\mathrm{b}}$ The same patient may have more than one surgical indication

'Urgency of surgery is defined as elective: surgery that is scheduled in advance because it does not involve a medical emergency, urgent: surgery required within

$<48 \mathrm{~h}$, emergent: surgery performed when the patients' life or well being are threatened

${ }^{d}$ Duration of surgery is the time between skin incision and closure of the incision

eDuration of anaesthesia is the time between start of induction and tracheal extubation or discharge from operation room if the mechanical ventilation

is continued

fDaytime surgery is defined as anaesthesia induction between 8:00 a.m. and 19:59 p.m. 
Table $\mathbf{2}$ Intraoperative ventilatory setting by group

\begin{tabular}{|c|c|c|c|c|c|}
\hline & $\begin{array}{l}\text { All patients } \\
(N=2034)\end{array}$ & $\begin{array}{l}\text { Closed } \\
\text { abdominal surgery } \\
(\mathrm{N}=906)\end{array}$ & $\begin{array}{l}\text { Open } \\
\text { abdominal surgery } \\
(N=1128)\end{array}$ & $P$-value & Absolute Difference \\
\hline \multicolumn{4}{|l|}{ Ventilation mode, \% (n/N) } & \multirow[t]{3}{*}{0.013} & \multirow{3}{*}{$\begin{array}{l}\text { Pressure-controlled } \\
4 \% \text { [1 to } 8 \%]\end{array}$} \\
\hline Volume-controlled & $77 \%(1571 / 2034)$ & $79 \%(895 / 906)$ & $75 \%(676 / 1128)$ & & \\
\hline Pressure-controlled & $23 \%(463 / 2034)$ & $21 \%(233 / 906)$ & $25 \%(230 / 1128)$ & & \\
\hline \multicolumn{6}{|l|}{ Tidal Volume } \\
\hline Absolute (ml) & 505 [465 to 570$]$ & $504[462$ to 570$]$ & 505 [465 to 572$]$ & 0.567 & 1 [24 to 25$]$ \\
\hline Per PBW (ml.kg $\left.{ }^{-1}\right)$ & $8.0[7.0$ to 9.0$]$ & 8.5 [7.6 to 9.5$]$ & $8.2[7.4$ to 9.2$]$ & 0.001 & $0.2[0.07$ to 0.5$]$ \\
\hline Per ABW $\left(\mathrm{ml} \cdot \mathrm{kg}^{-1}\right)$ & $7.0[6.0$ to 8.0$]$ & $6.8[5.8$ to 7.7$]$ & $7.0[6.1$ to 7.9$]$ & $<0.001$ & $0.2[0.1$ to 0.4$]$ \\
\hline Minute ventilation $\left(\mathrm{L} \cdot \mathrm{kg}^{-1}\right)$ & $6.0[6.0$ to 7.0$]$ & $6.5[5.8$ to 7.2$]$ & $6.3[5.5$ to 7.0$]$ & $<0.001$ & $0.2[0.1$ to 0.4$]$ \\
\hline \multicolumn{6}{|l|}{ Respiratory system compliance } \\
\hline Dynamic, ml.cm $\cdot \mathrm{H}_{2} \mathrm{O}^{-1}$ & 26 [21 to 32] & 25 [20 to 32] & 27 [21 to 33] & $<0.001$ & $2[0$ to 4$]$ \\
\hline Static, $\mathrm{ml} \cdot \mathrm{cm} \cdot \mathrm{H}_{2} \mathrm{O}^{-1}$ & $42[35$ to 50$]$ & $41[33$ to 50$]$ & $43[36$ to 51$]$ & $<0.001$ & 1 [0.4 to 2$]$ \\
\hline Routine recruitment maneuvers, \% (n/N) & $12 \%(238 / 2.029)$ & $13 \%(119 / 905)$ & $11 \%(119 / 1.124)$ & 0.087 & $2 \%[1$ to $5 \%]$ \\
\hline $\mathrm{FiO}_{2}, \%$ & $50[45$ to 56$]$ & 54 [48 to 70$]$ & $50[45$ to 63$]$ & $<0.001$ & $4[4$ to 10$]$ \\
\hline $\mathrm{SpO}_{2}, \%$ & 99 [98 to 100$]$ & 99 [98 to 100$]$ & $99[98$ to 100$]$ & $<0.001$ & $0[0 \text { to } 0]^{\mathrm{a}}$ \\
\hline $\mathrm{EtCO}_{2}, \mathrm{kPa}$ & $4.0[4.0$ to 5.0$]$ & $4.6[4.2$ to 4.9$]$ & $4.3[4.0$ to 4.7$]$ & $<0.001$ & $0.2[0.2$ to 0.6$]$ \\
\hline \multicolumn{6}{|l|}{ Airway pressures } \\
\hline \multicolumn{6}{|l|}{ Driving pressure } \\
\hline Time-weighted average $\left(\mathrm{cmH}_{2} \mathrm{O} \cdot\right.$ hour $\left.^{-1}\right)$ & $8[6$ to 11$]$ & $8[6$ to 11$]$ & 8 [6 to 10$]$ & 0.091 & $0.2[0.09$ to 1.2$]$ \\
\hline Maximum value $\left(\mathrm{cmH}_{2} \mathrm{O}\right)$ & $14[11$ to 18$]$ & $16[12$ to 20$]$ & $14[11$ to 17$]$ & $<0.001$ & $2[2$ to 7$]$ \\
\hline Minimum value $\left(\mathrm{cmH}_{2} \mathrm{O}\right)$ & $11[9$ to 14$]$ & $11[9$ to 15$]$ & $11[9$ to 14$]$ & 0.008 & $0[0$ to 17$]$ \\
\hline Coefficient of variation (\%) & $10[5$ to 20$]$ & 15 [6 to 26$]$ & $9[4$ to 15$]$ & $<0.001$ & $5[4$ to 8$]$ \\
\hline \multicolumn{6}{|l|}{ Peak pressure } \\
\hline Time-weighted average $\left(\mathrm{cmH}_{2} \mathrm{O} \cdot\right.$ hour $\left.^{-1}\right)$ & $12[9$ to 15$]$ & $11[9$ to 15$]$ & $12[9$ to 15$]$ & 0.414 & $0.2[0.1$ to 1.1$]$ \\
\hline Highest value $\left(\mathrm{cmH}_{2} \mathrm{O}\right)$ & $20[17$ to 24$]$ & 21 [18 to 26] & $19[16$ to 23$]$ & $<0.001$ & $2[2$ to 10$]$ \\
\hline Lowest value $\left(\mathrm{cmH}_{2} \mathrm{O}\right)$ & 16 [14 to 20] & 17 [14. to 20] & 16 [14 to 20$]$ & 0.011 & 1 [1 to 3$]$ \\
\hline Coefficient of variation (\%) & $8[4$ to 15$]$ & $11[5$ to 19$]$ & 7 [3 to 12] & $<0.001$ & $5[3$ to 6$]$ \\
\hline \multicolumn{6}{|l|}{ PEEP } \\
\hline Time-weighted average $\left(\mathrm{cmH}_{2} \mathrm{O} \cdot\right.$ hour $\left.^{-1}\right)$ & 2 [1 to 3$]$ & $2[1$ to 4$]$ & $2[1$ to 3$]$ & 0.019 & $0[0$ to 0$]$ \\
\hline Highest value $\left(\mathrm{cmH}_{2} \mathrm{O}\right)$ & $5[2$ to 5$]$ & $5[2$ to 5$]$ & $5[2$ to 5$]$ & 0.255 & $0[0$ to 0$]$ \\
\hline Lowest value $\left(\mathrm{cmH}_{2} \mathrm{O}\right)$ & $4[0$ to 5$]$ & $4[0$ to 5$]$ & $3[0$ to 5$]$ & 0.186 & $1[1$ to 5$]$ \\
\hline Coefficient of variation (\%) & 0 [0 to 22] & 0 [0 to 22] & 0 [0 to 22$]$ & 0.579 & $0[0$ to 0$]$ \\
\hline
\end{tabular}

Data are presented as median [25th-75th percentile] or \% $(\mathrm{n} / \mathrm{N})$. For binary and continuous variables risk difference and median difference with confidence intervals are reported respectively. Abbreviations: $\mathrm{EtCO}_{2}$ End-tidal $\mathrm{CO}_{2}, \mathrm{FiO}_{2}$ Fraction of inspired oxygen, $\mathrm{SpO} \mathrm{O}_{2}$ Peripheral oxygen saturation, $\mathrm{OR}$ Odds ratio ${ }^{a}$ Difference between groups is significant but very small and masked by rounding process

finding, though, was not confirmed in the matched cohort analysis.

This analysis uses the database of a worldwide international multicentre prospective observational study as a convenience sample [10], strictly followed a plan, and was characterised by a robust method accounting for the multilevel data structure and allowing precise estimation and confounder control, even with seven or fewer events per confounder [17, 18]. Also, the outcome of interest, i.e., PPCs, was predefined, well-described, and largely followed the European Perioperative Clinical Outcome (EPCO) group definitions [19]. Furthermore, the study population was defined to minimise information and selection bias and to have a sufficient number of patients while keeping an acceptable number of timepoints at which $\Delta \mathbf{P}_{\mathbf{T W}}$ could be calculated per patient.

A recent metanalysis of individual trials on protective ventilation during general anaesthesia for cardiac or thoracic surgery found a significant association between $\Delta \mathbf{P}_{\mathrm{TW}}$ and PPCs (OR 1.16, 95\% CI 1.13 to 1.19; 
Table 3 Intraoperative and postoperative outcomes

\begin{tabular}{|c|c|c|c|c|}
\hline & $\begin{array}{l}\text { All patients } \\
(\mathrm{N}=2.034)\end{array}$ & $\begin{array}{l}\text { Closed } \\
\text { abdominal surgery } \\
(\mathrm{N}=906)\end{array}$ & $\begin{array}{l}\text { Open } \\
\text { abdominal surgery } \\
(\mathrm{N}=1.128)\end{array}$ & $P$ - value \\
\hline Severe PPC (composite), \% (n/N) & $5 \%(102 / 2.034)$ & $3 \%(28 / 906)$ & $7 \%(74 / 1.128)$ & 0.001 \\
\hline \multicolumn{5}{|l|}{ Intraoperative complications } \\
\hline Desaturation & $4 \%(73 / 2.026)$ & $3 \%(26 / 903)$ & $4 \%(47 / 1.123)$ & 0.148 \\
\hline Unplanned rescue maneuvers & $4 \%(87 / 2.026)$ & $4 \%(41 / 903)$ & $4 \%(46 / 1.123)$ & 0.704 \\
\hline Need for ventilatory pressure reduction & $4 \%(77 / 2.025)$ & $6 \%(57 / 903)$ & $2 \%(20 / 1.102)$ & $<0.001$ \\
\hline Expiratory flow limitation & $1 \%(14 / 2.015)$ & $1 \%(12 / 898)$ & $0 \%(2 / 1.117)$ & 0.005 \\
\hline Hypotension & $28 \%(562 / 2.027)$ & $20 \%(182 / 903)$ & $34 \%(380 / 1.124)$ & $<0.001$ \\
\hline Use of vasopressors & $23 \%(469 / 2.027)$ & $17 \%(153 / 903)$ & $28 \%(316 / 1.122)$ & $<0.001$ \\
\hline New arrhythmia onset & $1 \%(13 / 2.027)$ & $0 \%(2 / 903)$ & $1 \%(11 / 1.124)$ & 0.065 \\
\hline \multicolumn{5}{|l|}{ Individual PCCs } \\
\hline Acute respiratory failure & $3 \%(58 / 2.034)$ & $2 \%(21 / 906)$ & $3 \%(37 / 1.128)$ & 0.245 \\
\hline Need for mechanical ventilation & $2 \%(44 / 2.034)$ & $1 \%(11 / 906)$ & $3 \%(33 / 1.128)$ & 0.013 \\
\hline Acute respiratory distress syndrome & $0 \%(6 / 2.034)$ & 0\% (0/906) & $0 \%(6 / 1.128)$ & 0.074 \\
\hline Pneumonia & $0 \%(16 / 2.034)$ & $0 \%(2 / 906)$ & $1 \%(14 / 1.128)$ & 0.019 \\
\hline Pneumothorax & $0 \%(4 / 2.034)$ & 0\% (0/906) & $0 \%(4 / 1.128)$ & 0.186 \\
\hline In-hospital mortality & $1 \%(22 / 1.892)$ & 0\% (3/838) & $2 \%(19 / 1.054)$ & 0.007 \\
\hline Length of stay (days) & 3 [1 to 5$]$ & 1 [0 to 3] & 5 [2 to 8$]$ & $<0.001$ \\
\hline
\end{tabular}

Data are presented as median [25th-75th percentile] or $\%(n / N)$

PPC Postoperative pulmonary complications

$p<0.0001$ ) [5]. We found an almost identical association in patients undergoing closed abdominal surgery. Thus, our results confirm that $\Delta \mathbf{P}_{\mathbf{T W}}$ is a promising target for interventions to prevent PPCs after closed abdominal surgery. The sensitivity analysis showed that the association between $\Delta \mathbf{P}_{\mathrm{TW}}$ and PPCs was lower in patients who underwent a closed surgical procedure. However, this was not confirmed in the propensity score matched analysis, probably because of smaller sample size due to the matching procedure.

$\Delta \mathrm{P}$ is an indicator of the amount of strain delivered to the respiratory system during mechanical ventilation [7]. Several studies investigated the effect of pneumoperitoneum on respiratory mechanics. Pneumoperitoneum was consistently found to decrease chest wall compliance, whereas lung compliance seems mostly spared by it [20-27]. Thus, inferring the amount of lung strain from plateau pressure and PEEP during pneumoperitoneum is challenging, since the part of the rise in plateau pressure caused by chest wall stiffening should not be regarded as a rise in lung strain [28]. Consequently, a higher $\Delta \mathrm{P}$ during closed abdominal surgery is often seen as innocent. The current analysis results reject this assumption, as the association of $\triangle \mathrm{P}$ with PPCs was stronger in patients undergoing closed abdominal surgery than in patients undergoing open abdominal surgery.

Pneumoperitoneum can affect lung mechanics in several ways [20-27]. A cranial shift of the diaphragm during laparoscopic surgery increases alveolar collapse, especially in lung parts close to the diaphragm. This is particularly true in upper abdominal surgery, which was the most common surgical procedure in patients undergoing closed surgery in the here studied cohort $[29,30]$. PEEP may partially prevent this, and usually only when using high PEEP [31]. In the patients studied here, mostly low PEEP was used, regardless of the group. Additional studies are needed to test how high PEEP affects the association between $\triangle \mathrm{P}$ with $\mathrm{PPCs}$ during pneumoperitoneum. Also, we found that $\Delta \mathrm{P}$ was higher in patients undergoing closed surgery than in patients undergoing open abdominal surgery. However, open abdominal surgery lasted longer, resulting in a comparable $\Delta \mathbf{P}_{\mathbf{T W}}$ in the two groups. The higher absolute $\Delta \mathrm{P}$ was compensated for by a shorter duration of intraoperative ventilation, and vice versa. Using the $\Delta \mathbf{P}_{\mathrm{Tw}}$ allowed us to estimate an exposure limit threshold to an injurious factor as in occupational health. The steeper increase in probability of PPCs above a $20 \mathrm{~cm} \mathrm{H}_{2} \mathrm{O} \cdot$ hour $^{-1}$ found in the sensitivity analysis can be related to an increase in collapsed lung tissue.

As expected, PPCs occurred more frequently in open abdominal surgery patients. An increased baseline risk could explain this due to typical differences in patient characteristics and the duration and the type of surgery. However, this finding strengthens the current analysis since we observed the association even in a cohort of 


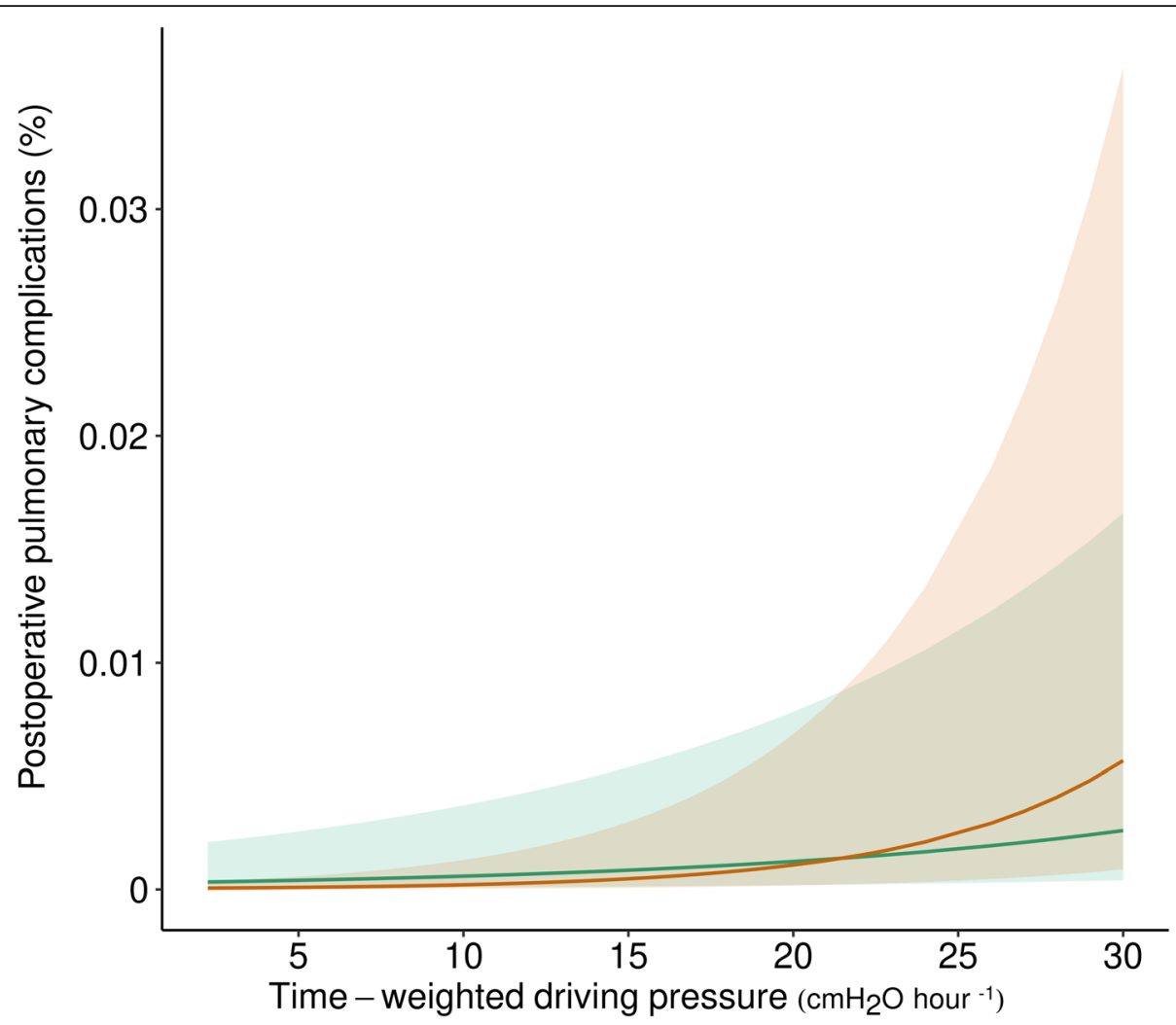

Fig. 3 Marginal effect plot of time-weighted average driving pressure on the probability of postoperative pulmonary complications by type of surgery. Green: open surgery, Orange: closed surgery; solid lines are estimated marginal mean effect, and bandwidths are $95 \%$ confidence intervals

patients, i.e., closed abdominal surgery, at low risk for PPCs and even after controlling for confounding effects with propensity score analysis.

Several intraoperative ventilation approaches, like the use of recruitment manoeuvres and higher PEEP, may result in a lower $\Delta \mathrm{P}[32,33]$. Findings of a metanalysis including clinical trials on intraoperative ventilation suggest that PEEP titrations that resulted in a $\triangle \mathrm{P}$ rise increased the risk of PPCs [5]. One randomised clinical trial showed an intraoperative PEEP strategy targeting the best compliance to reduce PPCs, though this was only a secondary endpoint in that study [34]. Thus, the best approach to minimise PPCs remains a matter of debate.

$\Delta \mathbf{P}_{\text {TW }}$ was associated with intraoperative adverse events in both closed and open surgery patients. Among all adverse events, airway pressure reduction was more frequently needed in closed surgery group underlining the need for ventilation strategies to lower peak and plateau pressures in this group of patients reflecting unacceptable high airway pressure during surgery.

Several limitations must be acknowledged. We used the parent LAS VEGAS definition of PPCs. This definition differs from what was somewhat recently proposed [1], but they remain reasonably comparable. The protocol of the LAS VEGAS study did not include the collection of oesophageal pressure recordings. Information regarding surgical positioning was not collected, and intra-abdominal pressure levels were also not recorded in the database of the LAS VEGAS study. Both could influence $\Delta \mathbf{P}_{\mathrm{TW}}$, though [35-37]. Due to the additional strict exclusion criteria, we excluded a considerable number of patients. Thus, the findings of this analysis need confirmation in other studies. Also, some patients had only a few timepoints at which $\Delta \mathrm{P}$ could be calculated. Furthermore, we only included patients with an endotracheal tube and patients who received controlled ventilation, limiting our focus on a specific type of intraoperative airway device and ventilation mode. Of note, $25 \%$ of patients had a Body Mass Index $(\mathrm{BMI})>30 \mathrm{~kg} \cdot \mathrm{m}^{-2}$. Extrapolating this analysis's findings to obese or morbidly obese patients should be done with some caution. Also, the original LAS VEGA $\mathrm{S}$ study was performed 7 years ago. Since then, there could have been changes in clinical practice, e.g., in the use of 'Enhanced Recovery After Surgery' (ERAS) pathways and muscle relaxant monitoring during and reversal at the end of surgery. Although the time gap between research findings and practice changes usually lasts longer than a decade [38-40], still could be that more immediate changes may affect the associations. Finally, we did not set any a priori effect threshold nor multiple comparisons 
correction; hence the results' statistical significance and the exploratory nature of secondary outcome analysis must be confirmed in future trials.

\section{Conclusions}

$\Delta \mathrm{P}_{\mathrm{TW}}$ is associated with the occurrence of PPCs and intraoperative adverse events in abdominal surgery. These associations are present regardless of the type of surgical approach and depend on the duration and actual $\Delta \mathrm{P}$. Both in patients undergoing open or closed abdominal surgery, the $\Delta \mathrm{P}$ is a promising target for future strategies to reduce PPCs.

\section{Supplementary Information}

The online version contains supplementary material available at https://doi. org/10.1186/s12871-021-01268-y.

Additional file 1: Table 1. Patient and surgery related characteristics.

Table 2. Intraoperative venitlatory setting by group.

Additional file 2: Table S1. Definition of postoperative pulmonary complications. Table S2. Definition of intraoperative complications. Table S3. Number of data available at each time point. Table S4 Patients demographics and surgery-related characteristics in the matched cohort for type of surgery. Table S5. Intraoperative and postoperative outcomes in matched cohort for type of surgery. Table S6. Mixed multivariable logistic regression in matched cohort for postoperative pulmonary complications. Figure S1. Time weighted average and coefficient of variation calculation. Figure S2. Summary plot of covariate balance for time-weighted $\Delta \mathrm{P}$ before (red line) and after (blue line) conditioning for open surgery. Figure S3. Summary plot of covariate balance before (red line) and after (blue line) conditioning for closed surgery. A: time-weighted; B: Highest value; C: Lowest Value; D: Coefficient of variation. Figure S4. Residuals plot for postoperative pulmonary complications (PPCs) and intraoperative adverse events (AEs). A: PPCs in Open surgery; B: PPCs in closed surgery; C; AEs in open surgery; $D$ : AEs in closed surgery.

\section{Abbreviations}

$\Delta P$ : Driving pressure; $\Delta P_{T W}$ : Time-weighted average $\Delta P$; $V_{T}$ : Tidal volume; PEEP: Positive end-expiratory pressure; STROBE: Strengthening the reporting of observational studies in epidemiology; ARISCAT: Assess Respiratory Risk in Surgical Patients in Catalonia; AUC: Area Under Curve; RR: Risk ratio; OR: Odds ratio; BMI: Body Mass Index; EPCO: European Perioperative Clinical Outcome; ERAS: Enhanced Recovery After Surgery'

\section{Acknowledgments}

The LAS VEGAS-investigators

AUSTRIA

LKH Graz, Graz: Wolfgang Kroell, Helfried Metzler, Gerd Struber, Thomas Wegscheider

AKH Linz, Linz: Hans Gombotz

Medical University Vienna: Michael Hiesmayr, Werner Schmid, Bernhard

Urbanek

BELGIUM

UCL-Cliniques Universitaires Saint Luc Brussels: David Kahn, Mona Momeni,

Audrey Pospiech, Fernande Lois, Patrice Forget, Irina Grosu

Universitary Hospital Brussels (UZ Brussel): Jan Poelaert, Veerle van

Mossevelde, Marie-Claire van Malderen

Het Ziekenhuis Oost Limburg (ZOL), Genk: Dimitri Dylst, Jeroen van

Melkebeek, Maud Beran

Ghent University Hospital, Gent: Stefan de Hert, Luc De Baerdemaeker, Bjorn Heyse, Jurgen Van Limmen, Piet Wyffels, Tom Jacobs, Nathalie Roels, Ann De Bruyne

Maria Middelares, Gent: Stijn van de Velde
European Society of Anaesthesiology, Brussels: Brigitte Leva, Sandrine Damster, Benoit Plichon

BOSNIA HERZEGOVINA

General Hospital 'prim Dr Abdulah Nakas' Sarajevo: Marina Juros-Zovko,

Dejana Djonović- Omanović

CROATIA

General Hospital Cakovec, Cakovec: Selma Pernar

General Hospital Karlovac, Karlovac: Josip Zunic, Petar Miskovic, Antonio

Zilic

University Clinical Hospital Osijek, Osijek: Slavica Kvolik, Dubravka Ivic, Darija Azenic-Venzera, Sonja Skiljic, Hrvoje Vinkovic, Ivana Oputric

University Hospital Rijeka, Rijeka: Kazimir Juricic, Vedran Frkovic

General Hospital Dr J Bencevic, Slavonski Brod: Jasminka Kopic, Ivan Mirkovic University Hospital Center Split, Split: Nenad Karanovic, Mladen Carev, Natasa Dropulic

University Hospital Merkur, Zagreb: Jadranka Pavicic Saric, Gorjana Erceg,

Matea Bogdanovic Dvorscak

University Hospital Sveti Duh, Zagreb: Branka Mazul-Sunko, Anna Marija

Pavicic, Tanja Goranovic

University Hospital, Medical school, "Sestre milosrdnice" (Sister of Charity),

Zagreb: Branka Maldini, Tomislav Radocaj, Zeljka Gavranovic, Inga Mladic-

Batinica, Mirna Sehovic

CZECH REPUBLIC

University Hospital Brno, Brno: Petr Stourac, Hana Harazim, Olga Smekalova,

Martina Kosinova, Tomas Kolacek, Kamil Hudacek, Michal Drab

University Hospital Hradec Kralove, Hradec Kralove: Jan Brujevic, Katerina

Vitkova, Katerina Jirmanova

University Hospital Ostrava, Ostrava: Ivana Volfova, Paula Dzurnakova,

Katarina Liskova

Nemocnice Znojmo, Znojmo: Radovan Dudas, Radek Filipsky

EGYPT

El Sahel Teaching hospital, Cairo: Samir el Kafrawy

Kasr Al-Ainy Medical School, Cairo University: Hisham Hosny Abdelwahab,

Tarek Metwally, Ahmed Abdel-Razek

Beni Sueif University Hospital, Giza: Ahmed Mostafa El-Shaarawy, Wael Fathy

Hasan, Ahmed Gouda Ahmed

Fayoum University Hospital, Giza: Hany Yassin, Mohamed Magdy, Mahdy

Abdelhady

Suis medical Insurance Hospital, Suis: Mohamed Mahran

ESTONIA

North Estonia Medical Center, Tallinn: Eiko Herodes, Peeter Kivik, Juri

Oganjan, Annika Aun

Tartu University Hospital, Tartu: Alar Sormus, Kaili Sarapuu, Merilin Mall, Juri Karjagin

FRANCE

University Hospital of Clermont-Ferrand, Clermont-Ferrand: Emmanuel Futier, Antoine Petit, Adeline Gerard

Institut Hospitalier Franco-Britannique, Levallois-Perret: Emmanuel Marret,

Marc Solier

Saint Eloi University Hospital, Montpellier: Samir Jaber, Albert Prades

GERMANY

Fachkrankenhaus Coswig, Coswig: Jens Krassler, Simone Merzky

University Hospital Carl Gustav Carus, Dresden: Marcel Gama de Abreu,

Christopher Uhlig, Thomas Kiss, Anette Bundy, Thomas Bluth, Andreas

Gueldner, Peter Spieth, Martin Scharffenberg, Denny Tran Thiem, Thea Koch

Duesseldorf University Hospital, Heinrich-Heine University: Tanja Treschan,

Maximilian Schaefer, Bea Bastin, Johann Geib, Martin Weiss, Peter Kienbaum,

Benedikt Pannen

Diakoniekrankenhaus Friederikenstift, Hannover: Andre Gottschalk, Mirja

Konrad, Diana Westerheide, Ben Schwerdtfeger

University of Leipzig, Leipzig: Hermann Wrigge, Philipp Simon, Andreas

Reske, Christian Nestler

GREECE

'Alexandra' general hospital of Athens, Athens: Dimitrios Valsamidis,

Konstantinos Stroumpoulis

General air force hospital, Athens: Georgios Antholopoulos, Antonis

Andreou, Dimitris Karapanos

Aretaieion University Hospital, Athens: Kassiani Theodoraki, Georgios Gkiokas,

Marios-Konstantinos Tasoulis

Attikon University Hospital, Athens: Tatiana Sidiropoulou, Foteini

Zafeiropoulou, Panagiota Florou, Aggeliki Pandazi 
Ahepa University Hospital Thessaloniki, Thessaloniki: Georgia Tsaousi, Christos Nouris, Chryssa Pourzitaki

ISRAEL

The Lady Davis Carmel Medical Center, Haifa: Dmitri Bystritski, Reuven Pizov, Arieh Eden

ITALY

Ospedale San Paolo Bari, Bari: Caterina Valeria Pesce, Annamaria Campanile, Antonella Marrella

University of Bari 'Aldo Moro', Bari: Salvatore Grasso, Michele De Michele Institute for Cancer Research and treatment, Candiolo, Turin: Francesco Bona, Gianmarco Giacoletto, Elena Sardo

Azienda Ospedaliera per l'emergenza Cannizzaro, Catania: Luigi Giancarlo, Vicari Sottosanti

Ospedale Melegnano, Cernuso, Milano: Maurizio Solca

Azienda Ospedaliera - Universitaria Sant'Anna, Ferrara: Carlo Alberto Volta,

Savino Spadaro, Marco Verri, Riccardo Ragazzi, Roberto Zoppellari

Ospedali Riuniti Di Foggia - University of Foggia, Foggia: Gilda Cinnella,

Pasquale Raimondo, Daniela La Bella, Lucia Mirabella, Davide D'antini IRCCS AOU San Martino IST Hospital, University of Genoa, Genoa: Paolo Pelosi, Alexandre Molin, Iole Brunetti, Angelo Gratarola, Giulia Pellerano, Rosanna Sileo, Stefano Pezzatto, Luca Montagnani

IRCCS San Raffaele Scientific Institute, Milano: Laura Pasin, Giovanni Landoni, Alberto Zangrillo, Luigi Beretta, Ambra Licia Di Parma, Valentina Tarzia, Roberto Dossi, Marta Eugenia Sassone

Istituto europeo di oncologia - ieo, Milano: Daniele Sances, Stefano Tredici, Gianluca Spano, Gianluca Castellani, Luigi Delunas, Sopio Peradze, Marco Venturino Ospedale Niguarda Ca'Granda Milano, Milano: Ines Arpino, Sara Sher Ospedale San Paolo - University of Milano, Milano: Concezione Tommasino, Francesca Rapido, Paola Morelli

University of Naples "Federico II" Naples: Maria Vargas, Giuseppe Servillo

Policlinico 'P. Giaccone', Palermo: Andrea Cortegiani, Santi Maurizio Raineri,

Francesca Montalto, Vincenzo Russotto, Antonino Giarratano

Azienda Ospedaliero-Universitaria, Parma: Marco Baciarello, Michela Generali,

Giorgia Cerati

Santa Maria degli Angeli, Pordenone: Yigal Leykin

Ospedale Misericordia e Dolce - Us/4 Prato, Prato: Filippo Bressan, Vittoria Bartolini, Lucia Zamidei

University hospital of Sassari, Sassari: Luca Brazzi, Corrado Liperi, Gabriele Sales, Laura Pistidda

Insubria University, Varese: Paolo Severgnini, Elisa Brugnoni, Giuseppe

Musella, Alessandro Bacuzzi

REPUBLIC OF KOSOVO

Distric hospital Gjakova, Gjakove: Dalip Muhardri

University Clinical Center of Kosova, Prishtina: Agreta Gecaj-Gashi, Fatos

Sada

Regional Hospital 'Prim.Dr. Daut Mustafa', Prizren: Adem Bytyqi

LITHUANIA

Medical University Hospital, Hospital of Lithuanian University of Health

Sciences, Kaunas: Aurika Karbonskiene, Ruta Aukstakalniene, Zivile Teberaite, Erika Salciute

Vilnius University Hospital - Institute of Oncology, Vilnius: Renatas Tikuisis, Povilas Miliauskas

Vilnius University Hospital - Santariskiu Clinics, Vilnius: Sipylaite Jurate, Egle Kontrimaviciute, Gabija Tomkute

MALTA

Mater Dei Hospital, Msida: John Xuereb, Maureen Bezzina, Francis Joseph

Borg

THE NETHERLANDS

Academic Medical Centre, University of Amsterdam: Sabrine Hemmes, Marcus Schultz, Markus Hollmann, Irene Wiersma, Jan Binnekade, Lieuwe Bos VU University Medical Center, Amsterdam: Christa Boer, Anne Duvekot MC Haaglanden, Den Haag: Bas in 't Veld, Alice Werger, Paul Dennesen, Charlotte Severijns

Westfriesgasthuis, Hoorn: Jasper De Jong, Jens Hering, Rienk van Beek NORWAY

Haukeland University Hospital, Bergen: Stefan Ivars, Ib Jammer

Førde Central Hospital /Førde Sentral Sykehus, Førde: Alena Breidablik

Martina Hansens Hospital, Gjettum: Katharina Skirstad Hodt, Frode Fjellanger,

Manuel Vico Avalos

Bærum Hospital, Vestre Viken, Rud: Jannicke Mellin-Olsen, Elisabeth

Andersson
Stavanger University Hospital, Stavanger: Amir Shafi-Kabiri

PANAMA

Hospital Santo Tomás, Panama: Ruby Molina, Stanley Wutai, Erick Morais PORTUGAL

Hospital do Espírito Santo - Évora, E.P.E, Évora: Glória Tareco, Daniel Ferreira, Joana Amaral

Centro Hospitalar de Lisboa Central, E.P.E, Lisboa: Maria de Lurdes

Goncalves Castro, Susana Cadilha, Sofia Appleton

Centro Hospitalar de Lisboa Ocidental, E.P.E. Hospital de S. Francisco Xavier,

Lisboa: Suzana Parente, Mariana Correia, Diogo Martins

Santarem Hospital, Santarem: Angela Monteirosa, Ana Ricardo, Sara

Rodrigues

ROMANIA

Spital Orasenesc, Bolintin Vale: Lucian Horhota

Clinical Emergency Hospital of Bucharest, Bucharest: loana Marina Grintescu,

Liliana Mirea, Ioana Cristina Grintescu

Elias University Emergency Hospital, Bucharest: Dan Corneci, Silvius Negoita,

Madalina Dutu, loana Popescu Garotescu

Emergency Institute of Cardiovascular Diseases Inst. "Prof. C. C. Iliescu",

Bucharest: Daniela Filipescu, Alexandru Bogdan Prodan

Fundeni Clinical institute - Anaesthesia and Intensive Care, Bucharest:

Gabriela Droc, Ruxandra Fota, Mihai Popescu

Fundeni Clinical institute - Intensive Care Unit, Bucharest: Dana Tomescu, Ana Maria Petcu, Marian Irinel Tudoroiu

Hospital Profesor D Gerota, Bucharest: Alida Moise, Catalin-Traian Guran Constanta County Emergency Hospital, Constanta: Iorel Gherghina, Dan

Costea, Iulia Cindea

University Emergency County Hospital Targu Mures, Targu Mures: Sanda-

Maria Copotoiu, Ruxandra Copotoiu, Victoria Barsan, Zsolt Tolcser, Magda

Riciu, Septimiu Gheorghe Moldovan, Mihaly Veres

RUSSIA

Krasnoyarsk State Medical University, Krasnoyarsk: Alexey Gritsan, Tatyana

Kapkan, Galina Gritsan, Oleg Korolkov

Burdenko Neurosurgery Institute, Moscow: Alexander Kulikov, Andrey Lubnin Moscow Regional Research Clinical Institute, Moscow: Alexey Ovezov, Pavel

Prokoshev, Alexander Lugovoy, Natalia Anipchenko

Municipal Clinical Hospital 7, Moscow: Andrey Babayants, Irina Komissarova,

Karginova Zalina

Reanimatology Research Institute n.a. Negovskij RAMS, Moscow: Valery

Likhvantsev, Sergei Fedorov

SERBIA

Clinical Center of Vojvodina, Emergency Center, Novisad: Aleksandra Lazukic,

Jasmina Pejakovic, Dunja Mihajlovic

SLOVAKIA

National Cancer Institute, Bratislava: Zuzana Kusnierikova, Maria Zelinkova

F.D. Roosevelt teaching Hospital, Banská Bystrica: Katarina Bruncakova, Lenka

Polakovicova

Faculty Hospital Nové Zámky, Nové Zámky: Villiam Sobona

SLOVENIA

Institute of Oncology Ljubljana, Ljubljana: Barbka Novak-Supe, Ana Pekle-

Golez, Miroljub Jovanov, Branka Strazisar

University Medical Centre Ljubljana, Ljubljana: Jasmina Markovic-Bozic, Vesna

Novak-Jankovic, Minca Voje, Andriy Grynyuk, Ivan Kostadinov, Alenka

Spindler-Vesel

SPAIN

Hospital Sant Pau, Barcelona: Victoria Moral, Mari Carmen Unzueta, Carlos

Puigbo, Josep Fava

Hospital Universitari Germans Trias I Pujol, Barcelona: Jaume Canet, Enrique

Moret, Mónica Rodriguez Nunez, Mar Sendra, Andrea Brunelli, Frederic

Rodenas

University of Navarra, Pamplona: Pablo Monedero, Francisco Hidalgo

Martinez, Maria Jose Yepes Temino, Antonio Martínez Simon, Ana de Abajo Larriba

Corporacion Sanitaria Parc Tauli, Sabadell: Alberto Lisi, Gisela Perez, Raquel Martinez

Consorcio Hospital General Universitario de Valencia, Valencia: Manuel

Granell, Jose Tatay Vivo, Cristina Saiz Ruiz, Jose Antonio de Andrés Ibañez

Hospital Clinico Valencia, Valencia: Ernesto Pastor, Marina Soro, Carlos

Ferrando, Mario Defez

Hospital Universitario Rio Hortega, Valladolid: Cesar Aldecoa Alvares-

Santullano, Rocio Perez, Jesus Rico 


\section{SWEDEN}

Central Hospital in Kristianstad: Monir Jawad, Yousif Saeed, Lars Gillberg TURKEY

Ufuk University Hospital Ankara, Ankara: Zuleyha Kazak Bengisun, Baturay Kansu Kazbek

Akdeniz University Hospital, Antalya: Nesil Coskunfirat, Neval Boztug, Suat Sanli, Murat Yilmaz, Necmiye Hadimioglu

Istanbul University, Istanbul medical faculty, Istanbul: Nuzhet Mert Senturk, Emre Camci, Semra Kucukgoncu, Zerrin Sungur, Nukhet Sivrikoz

Acibadem University, Istanbul: Serpil Ustalar Ozgen, Fevzi Toraman

Maltepe University, Istanbul: Onur Selvi, Ozgur Senturk, Mine Yildiz

Dokuz Eylül Universitesi Tip Fakültesi, Izmir: Bahar Kuvaki, Ferim Gunenc,

Semih Kucukguclu, Sule Ozbilgin

Şifa University Hospital, Izmir: Jale Maral, Seyda Canli

Selcuk University faculty of medicine, Konya: Oguzhan Arun, Ali Saltali, Eyup

Aydogan

Fatih Sultan Mehmet Eğitim Ve Araștirma Hastanesi, Istanbul: Fatma Nur Akgun, Ceren Sanlikarip, Fatma Mine Karaman UKRAINE

Institute Of Surgery And Transplantology, Kiev: Andriy Mazur

Zaporizhzhia State Medical University, Zaporizhzhia: Sergiy Vorotyntsev UNITED KINGDOM

SWARM Research Collaborative: for full list of SWARM contributors please see www.ukswarm.com

Northern Devon Healthcare NHS Trust, Barnstaple: Guy Rousseau, Colin Barrett, Lucia Stancombe

Golden Jubilee National Hospital, Clydebank, Scotland: Ben Shelley, Helen Scholes Darlington Memorial Hospital, County Durham and Darlington Foundation NHS Trust, Darlington: James Limb, Amir Rafi, Lisa Wayman, Jill Deane Royal Derby Hospital, Derby: David Rogerson, John Williams, Susan Yates, Elaine Rogers

Dorset County Hospital, Dorchester: Mark Pulletz, Sarah Moreton, Stephanie Jones The Princess Alexandra NHS Hospital Trust, Essex: Suresh Venkatesh,

Maudrian Burton, Lucy Brown, Cait Goodall

Royal Devon and Exeter NHS Foundation Trust, Exeter: Matthew Rucklidge,

Debbie Fuller, Maria Nadolski, Sandeep Kusre

Hospital James Paget University Hospital NHS Foundation Trust, Great

Yarmouth: Michael Lundberg, Lynn Everett, Helen Nutt

Royal Surrey County Hospital NHS Foundation Trust, Guildford: Maka Zuleika,

Peter Carvalho, Deborah Clements, Ben Creagh-Brown

Kettering General Hospital NHS Foundation Trust, Kettering: Philip Watt,

Parizade Raymode

Barts Health NHS Trust, Royal London Hospital, London: Rupert Pearse, Otto Mohr, Ashok Raj, Thais Creary

Newcastle Upon Tyne Hospitals NHS Trust The Freeman Hospital High

Heaton, Newcastle upon Tyne: Ahmed Chishti, Andrea Bell, Charley Higham,

Alistair Cain, Sarah Gibb, Stephen Mowat

Derriford Hospital Plymouth Hospitals NHS Trust, Plymouth: Danielle

Franklin, Claire West, Gary Minto, Nicholas Boyd

Royal Hallamshire Hospital, Sheffield: Gary Mills, Emily Calton, Rachel Walker, Felicity Mackenzie, Branwen Ellison, Helen Roberts

Mid Staffordshire NHS, Stafford: Moses Chikungwa, Clare Jackson

Musgrove Park Hospital, Taunton: Andrew Donovan, Jayne Foot, Elizabeth Homan South Devon Healthcare NHS Foundation Trust /Torbay Hospital, Torquay,

Torbay: Jane Montgomery, David Portch, Pauline Mercer, Janet Palmer

Royal Cornwall Hospital, Truro: Jonathan Paddle, Anna Fouracres, Amanda Datson, Alyson Andrew, Leanne Welch

Mid Yorkshire Hospitals NHS Trust; Pinderfields Hospital, Wakefield: Alastair Rose, Sandeep Varma, Karen Simeson

Sandwell and West Birmingham NHS Trust, West Bromich: Mrutyunjaya

Rambhatla, Jaysimha Susarla, Sudhakar Marri, Krishnan Kodaganallur, Ashok

Das, Shivarajan Algarsamy, Julie Colley

York Teaching Hospitals NHS Foundation Trust, York: Simon Davies,

Margaret Szewczyk, Thomas Smith

UNITED STATES

University of Colorado School of Medicine/University of Colorado Hospital,

Aurora: Ana Fernandez- Bustamante, Elizabeth Luzier, Angela Almagro

Massachusetts General Hospital, Boston: Marcos Vidal Melo, Luiz Fernando, Demet Sulemanji

Mayo Clinic, Rochester: Juraj Sprung, Toby Weingarten, Daryl Kor, Federica Scavonetto, Yeo Tze

\section{Authors' contributions}

GM, ASN and MJS: Designed the study; GM, ASN, SNTH: Wrote the protocol; GM, ASN, LB, MJS: Collected the data from the original database; GM, ASN, ODC: Analyzed the data; GH, SJ, MH, GHM, MFVM, RMP, CP, WS, PS, HW, MWH, PP, MGdA, MJS: made substantial contribution to data interpretation; GM, wrote the manuscript under the supervision of PP and MJS. The authors read and approved the final manuscript.

\section{Funding}

The LAS VEGAS study was endorsed and partly funded by a restricted research grant from the European Society of Anesthesiology through their Clinical Trial Network.

\section{Availability of data and materials}

The data as well as the code used for analysis are available from the corresponding author upon reasonable request.

\section{Ethics approval and consent to participate}

The original study protocol was approved by the ethical committee of the Academic Medical Center, Amsterdam, the Netherlands

(W12_190\#12.17.0227). Each participating centre obtained approval from their institutional review board if needed, and patients were included after obtaining written informed consent when dictated by national or regional legislation.

\section{Consent for publication}

Not applicable.

\section{Competing interests}

G. Mazzinari: No interest declared; A. Serpa Neto: No interest declared; S.N.T. Hemmes: No interest declared; G. Hedenstierna: No interest declared; S. Jaber: No interest declared; M. Hiesmayr: No interest declared; M.W. Hollmann: Executive Section Editor Pharmacology with Anesthesia \& Analgesia, Section Editor Anesthesiology with Journal of Clinical Medicine, and CSL Behring, no conflict of interest with the current work; G.H. Mills: No interest declared; M.F. Vidal Melo: is funded by NIH/NHLBI grant UH3HL140177; R.M. Pearse: No interest declared; C. Putensen: No interest declared; W. Schmid: No interest declared; P. Severgnini: No interest declared; H.Wrigge: No interest declared; O. Diaz-Cambronero: had received a Merck Sharp \& Dohme investigator-initiated grant (protocol code \#53607). Sponsors and funders have no roles in study design, analysis of data or reporting. Also received speakers fees for lecture and medical advice from Merck Sharp \& Dohme, no conflict of interest with the current work; L.Ball: No interest declared; M. Gama de Abreu: Ambu, GE Healthcare, ZOLL consulting fees, no conflict of interest with the current work; P.Pelosi: No interest declared; M.J.Schultz: No interest declared.

\section{Author details}

${ }^{1}$ Research Group in Perioperative Medicine, Hospital Universitario y Politécnico la Fe, Avinguda de Fernando Abril Martorell 106, 46026 Valencia, Spain. ${ }^{2}$ Department of Anesthesiology, Hospital Universitario y Politécnico la $\mathrm{Fe}$, Valencia, Spain. ${ }^{3}$ Department of Critical Care Medicine, Hospital Israelita Albert Einstein, São Paulo, Brazil. ${ }^{4}$ Cardio-Pulmonary Department, Pulmonary Division, Faculdade de Medicina, Instituto do Coração, Hospital das Clinicas HCFMUSP, Universidade de Sao Paulo, Sao Paulo, Brazil. ${ }^{5}$ Department of Intensive Care \& Laboratory of Experimental Intensive Care and Anesthesiology (L.E.I.C.A), Academic Medical Center, Amsterdam, The Netherlands. ${ }^{6}$ Department of Medical Sciences, Clinical Physiology, Uppsala University, Uppsala, Sweden. ${ }^{7}$ PhyMedExp, INSERM U1046, CNRS UMR 9214, University of Montpellier, Montpellier, France. ${ }^{8}$ Division Cardiac, Thoracic, Vascular Anesthesia and Intensive Care, Medical University Vienna, Vienna, Austria. ${ }^{9}$ Operating Services, Critical Care and Anesthesia, Sheffield Teaching Hospitals, Sheffield and University of Sheffield, Sheffield, UK. ${ }^{10}$ Department of Anesthesia, Critical Care and Pain Medicine, Massachusetts General Hospital, Boston, USA. " 1 Queen Mary University of London, London, UK. ${ }^{12}$ Department of Anesthesiology and Intensive Care Medicine, University Hospital Bonn, Bonn, Germany. ${ }^{13}$ Department of Biotechnology and Sciences of Life, ASSTSettelaghi Ospedale di Circolo e Fondazione Macchi, University of Insubria, Varese, Italy. ${ }^{14}$ Department of Anesthesiology, Intensive Care and Emergency Medicine, Pain Therapy, Bergmannstrost Hospital, Halle, Germany.

${ }^{15}$ Policlinico San Martino Hospital - IRCCS for Oncology and Neurosciences, 
Genoa, Italy. ${ }^{16}$ Department of Surgical Sciences and Integrated Diagnostics, University of Genoa Italy, Genoa, Italy. ${ }^{17}$ Department of Anesthesiology and Intensive Care Therapy, Pulmonary Engineering Group, Technische Universität Dresden, Dresden, Germany. ${ }^{18}$ Mahidol-Oxford Tropical Medicine Research Unit (MORU), Mahidol University, Bangkok, Thailand. ${ }^{19}$ Nuffield Department of Medicine, University of Oxford, Oxford, UK.

Received: 12 November 2020 Accepted: 25 January 2021 Published online: 19 March 2021

\section{References}

1. Abbott TEF, Fowler AJ, Pelosi P, et al. A systematic review and consensus definitions for standardised end-points in perioperative medicine: pulmonary complications. Br J Anaesth. 2018;120:1066-79.

2. Miskovic A, Lumb AB. Postoperative pulmonary complications. Br J Anaesth. 2017;118:317-34.

3. Khuri SF, Henderson WG, DePalma RG, Mosca C, Healey NA, Kumbhani DJ. Determinants of long-term survival after major surgery and the adverse effect of postoperative complications. Ann Surg. 2005;242:326-43.

4. Serpa Neto A, Hemmes SNT, Barbas CSV, et al. Protective versus conventional ventilation for surgery. Anesthesiology. 2015;123:66-78.

5. Neto AS, Hemmes SNT, Barbas CSV, et al. Association between driving pressure and development of postoperative pulmonary complications in patients undergoing mechanical ventilation for general anaesthesia: a metaanalysis of individual patient data. Lancet Respir Med. 2016;4:272-80.

6. Ladha K, Melo MFV, McLean DJ, Wanderer JP, Grabitz SD, Kurth T, et al. Intraoperative protective mechanical ventilation and risk of postoperative respiratory complications: hospital based registry study. Br Med J. 2015;351: h3646.

7. Williams EC, Motta-Ribeiro GC, Vidal Melo MF. Driving pressure and Transpulmonary pressure: how do we guide safe mechanical ventilation? Anesthesiology. 2019;131:155-63.

8. De Jong MAC, Ladha KS, Melo MFV, Staehr-Rye AK, Bittner EA, Kurth T, et al. Differential effects of intraoperative positive end-expiratory pressure (PEEP) on respiratory outcome in major abdominal surgery versus craniotomy. Ann Surg. 2016;264:362-9.

9. Wirth S, Biesemann A, Spaeth J, Schumann S. Pneumoperitoneum deteriorates intratidal respiratory system mechanics: an observational study in lung-healthy patients. Surg Endosc. 2017;31:753-60.

10. LAS VEGAS investigators. Epidemiology, practice of ventilation and outcome for patients at increased risk of postoperative pulmonary complications: LAS VEGAS - an observational study in 29 countries. Eur J Anaesthesiol. 2017;34: 492-507.

11. Nichol A, Bailey M, Egi M, et al. Dynamic lactate indices as predictors of outcome in critically ill patients. Crit Care. 2011;15:R242.

12. Imai L, Ratkovic M. CBPS: covariate balancing propensity score. J R I State Dent Soc. 2014;76:243-63.

13. Canet J, Gallart L, Gomar C, et al. Prediction of postoperative pulmonary complications in a population-based surgical cohort. Anesthesilogy. 2010; 113:1338-50.

14. Mazo V, Sabaté S, Canet J, et al. Prospective external validation of a predictive score for postoperative pulmonary complications. Anesthesiology. 2014;121:219-31.

15. Dunkler D, Plischke M, Leffondré K, Heinze G. Augmented backward elimination: a pragmatic and purposeful way to develop statistical models. PLoS One. 2014:9:1-19.

16. Myers J, Rassen J, Gagne J, et al. Effects of adjusting for instrumental variables on bias and precision of effect estimates. Am J Epidemiol. 2011; 174:1213-22.

17. Cepeda MS, Boston R, Farrar JT, Strom BL. Comparison of logistic regression versus propensity score when the number of events is low and there are multiple confounders. Am J Epidemiol. 2003;158:280-7.

18. Austin PC. Assessing the performance of the generalised propensity score for estimating the effect of quantitative or continuous exposures on binary outcomes. Stat Med. 2018;37:1874-94.

19. Jammer I, Wickboldt N, Sander M, et al. Standards for definitions and use of outcome measures for clinical effectiveness research in perioperative medicine: European perioperative clinical outcome (EPCO) definitions: a statement from the ESA-ESICM joint taskforce on perioperative outcome measur. Eur J Anaesthesiol. 2015;32:88-105.
20. Cinnella G, Grasso S, Spadaro S, et al. Effects of recruitment maneuver and positive end-expiratory pressure on respiratory mechanics and transpulmonary pressure during laparoscopic surgery. Anesthesiology. 2013; 118:114-22.

21. Fahy BG, Nagle SE, Njoku MJ, Flowers JL, Barnas GM. The effects of increased abdominal pressure on Lung and Chest Wall mechanics during laparoscopic surgery. Anesth Analg. 1995;81:744-50.

22. Maracajá-Neto LF, Verçosa N, Roncally AC, Giannella A, Bozza FA, Lessa MA. Beneficial effects of high positive end-expiratory pressure in lung respiratory mechanics during laparoscopic surgery. Acta Anaesthesiol Scand. 2009;53:210-7.

23. Mutoh T, Lamm WJE, Embree LJ, Hildebrandt J, Albert RK. Abdominal distension alters regional pleural pressures and chest wall mechanics in pigs in vivo. J Appl Physiol. 1991;70:2611-8.

24. Brandão JC, Lessa MA, Motta-Ribeiro G, et al. Global and regional respiratory mechanics during robotic-assisted laparoscopic surgery. Anesth Analg. 2019; 129:1564-73.

25. Pelosi P, Foti G, Cereda M, Vicardi P, Gattinoni L. Effects of carbon dioxide insufflation for laparoscopic cholecystectomy on the respiratory system. Anaesthesia. 1996:51:744-9.

26. Kubiak BD, Gatto LA, Jimenez EJ, et al. Plateau and Transpulmonary pressure with elevated intra-abdominal pressure or atelectasis. J Surg Res. 2010;159: e17-24.

27. Cortes-Puentes GA, Gard KE, Adams AB, Faltesek KA, Anderson CP, Dries DJ, et al. Value and limitations of transpulmonary pressure calculations during intra-abdominal hypertension. Crit Care Med. 2013;41:1870-7.

28. Loring SH, Topulos GP, Hubmayr RD. Transpulmonary pressure: the importance of precise definitions and limiting assumptions. Am J Respir Crit Care Med. 2016;194:1452-7.

29. Andersson LE, Bååth $M$, Thörne A, Aspelin P, Odeberg-Wernerman S. Effect of carbon dioxide pneumoperitoneum on development of atelectasis during anesthesia, examined by spiral computed tomography. Anesthesiology. 2005;102:293-9.

30. Pereira SM, Tucci MR, Morais CCA, et al. Individual positive end-expiratory pressure settings optimise intraoperative mechanical ventilation and reduce postoperative atelectasis. Anesthesiology. 2018;129:1070-81.

31. Mazzinari G, Diaz-Cambronero O, Alonso-Iñigo JM, et al. Intraabdominal pressure targeted positive end-expiratory pressure during laparoscopic surgery: an open-label, nonrandomized, crossover, clinical trial. Anesthesiology. 2020;132:667-77.

32. D'Antini D, Rauseo M, Grasso S, et al. Physiological effects of the open lung approach during laparoscopic cholecystectomy: focus on driving pressure. Minerva Anestesiol. 2018;84:159-67.

33. Eichler L, Truskowska K, Dupree A, Busch P, Goetz AE, Zöllner C. Intraoperative ventilation of morbidly obese patients guided by Transpulmonary pressure. Obes Surg. 2018;28:122-9.

34. Ferrando C, Soro M, Unzueta C, et al. Individualised perioperative open-lung approach versus standard protective ventilation in abdominal surgery (iPROVE): a randomised controlled trial. Lancet Respir Med. 2018;6:193-203.

35. Gainsburg DM. Anesthetic concerns for robotic-assisted laparoscopic radical prostatectomy. Minerva Anestesiol. 2012;78:596-604.

36. Sharma KC, Brandstetter RD, Brensilver JM, Lung LD. Cardiopulmonary physiology and pathophysiology as a consequence of laparoscopic surgery. Chest. 1996;51:810-5.

37. Fahy BG. Cardiopulmonary effects of laparoscopic surgery, revisited. Chest. 1997;111:1787-8.

38. Lane-Fall MB, Cobb BT, Cené CW, Beidas RS. Implementation science in perioperative care. Anesthesiol Clin. 2018;36:1-15.

39. Morris ZS, Wooding S, Grant J. The answer is 17 years, what is the question: understanding time lags in translational research. J R Soc Med. 2011;104: 510-20

40. Wong A. Closing the gap: applying the theoretical domains framework to improve knowledge translation. Can J Anaesth. 2017;64:569-73.

\section{Publisher's Note}

Springer Nature remains neutral with regard to jurisdictional claims in published maps and institutional affiliations. 